The experience of being an advanced practice nurse within Australian acute care settings: A systematic review of qualitative evidence

A thesis submitted as fulfilment for the award of Master of Philosophy (Clinical Science)

October 2012

University of Adelaide - in conjunction with the Joanna Briggs Institute Mary-Anne Ramis 


\section{Supervisory Team}

Professor Alan Pearson RN, PhD, FRCNA, FAAG, FRCN

Professor of Evidence Based Healthcare and Executive Director, The Joanna

Briggs Institute, Faculty of Health Sciences, The University of Adelaide,

South Australia, Australia. 5005

Dr Chiung-Jung (Jo) Wu RN, BN, MN (Intensive Care) DrHlthSc, MRCNA

School of Nursing, Faculty of Health

Institute of Health and Biomedical Innovation (IHBI)

Queensland University of Technology (QUT), Kelvin Grove, Brisbane.

Queensland, Australia. 4059. 


\section{Keywords}

Systematic Review

Advanced Practice

Advanced Practice Nurse

APN

Clinical Nurse Consultant

Clinical Nurse Specialist

Nurse Practitioner

Expert Nurse

Acute Care Settings

Hospital

Australia

Qualitative metasynthesis

Metasynthesis

Qualitative research

Phenomenology

Context 


\begin{abstract}
Background: Shortages of health care professionals and an ageing nursing workforce are some of the factors leading to the creation and evolution of many new nursing roles. Advanced practice nurses across the globe are working under many different titles and within various contexts, in order to address gaps within current health care systems. Comparison of roles between countries is difficult and possibly inappropriate due to Australia's unique environmental and demographic characteristics. A context-specific systematic review on the qualitative evidence of the experience of being an advanced practice nurse in Australia has not been undertaken previously, however it is imperative for nursing managers and leaders to understand the complexities of advanced nursing roles in order to effectively utilise and retain these experienced and valuable nurses.
\end{abstract}

Aim: This study aims to provide deeper understanding of the experience of being an advanced practice nurse working in Australian acute settings and identify personal, professional and organisational factors influencing experiences.

Methods: A three-step search strategy, following the Joanna Briggs Institute method was used to identify published and unpublished interpretive studies meeting set inclusion criteria. Critical appraisal and data extraction were completed the Joanna Briggs Institute Qualitative Assessment and Review Instruments.

Results: Following the search and appraisal process, four studies were assessed as meeting the inclusion criteria and from these, 216 findings were extracted. Six meta-syntheses under the headings of expert knowledge, confidence, education, relationships, negative experiences and patient centered experience were formed from the findings. 
Conclusion: This review has increased our understanding about the experience of being an advanced practice nurse in Australian acute care settings and provided evidence of the role being multifactorial and complex. The patient is central to the APN experience but organisational factors impact and influence their experience also. Health care organisations must be aware of the impact they have on the nurse's experience if they are to commit to nurse retention and patient safety. Nurses must continue to improve articulating their experiences in order to quantify the more intangible aspects of their practice.

Implications: There is a pragmatic aspect to this review as implications for practice are specific to the functioning of the advanced practice nurse in the Australian acute care environment. The complexity of the role has been highlighted which may assist to inform future research into other aspects of APN practice. 


\section{Table of Contents}

Supervisory Team

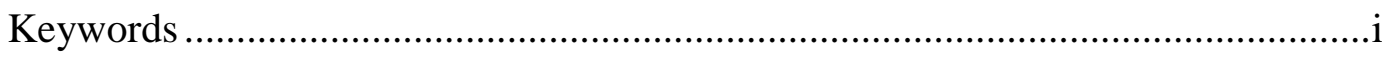

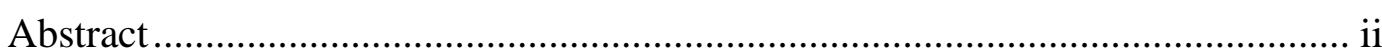

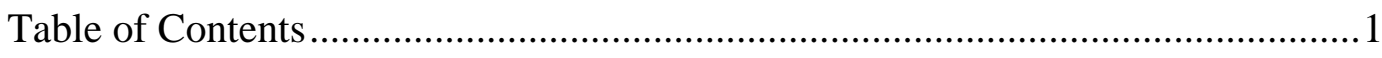

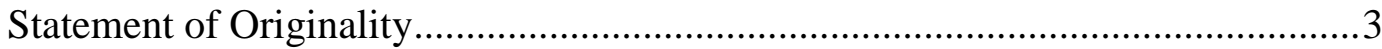

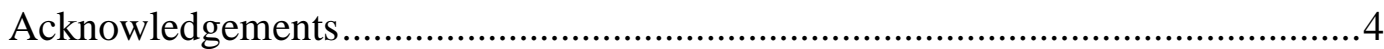

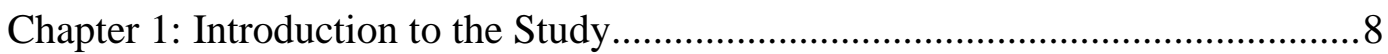

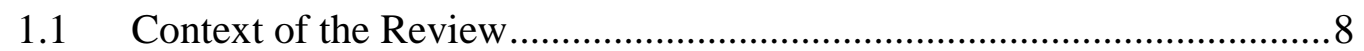

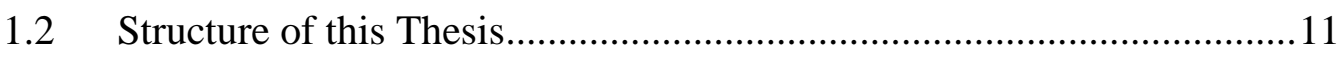

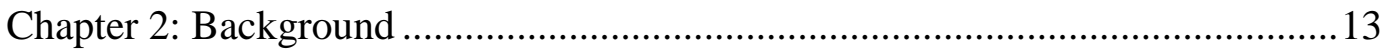

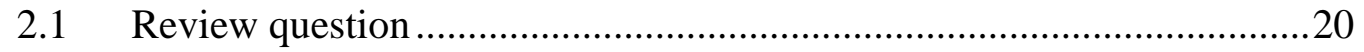

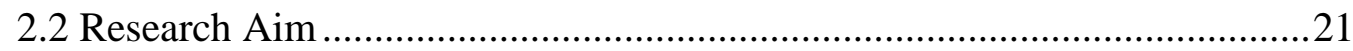

Chapter 3: Study Methods and Design ..........................................................22

3.2 Methodological basis for chosen approach to synthesis ........................24

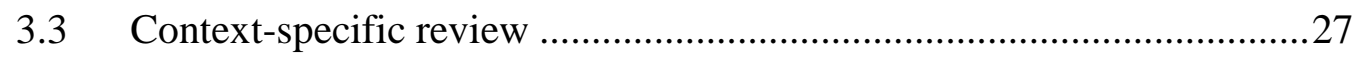

3.4 Criteria for Considering Studies for this Review ..................................29

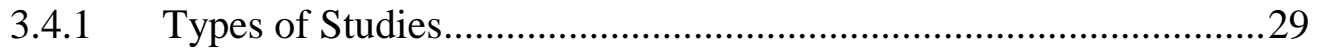

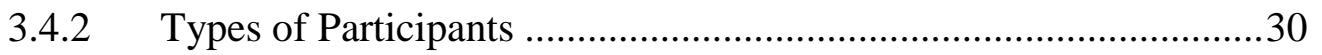

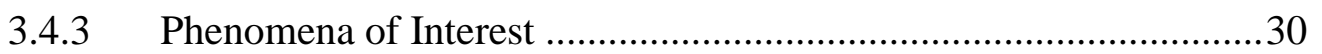

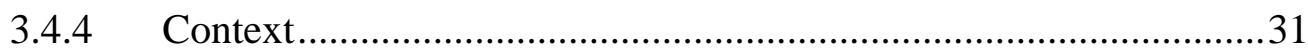



3.6 Assessment of Methodological Quality/ Critical Appraisal.....................33

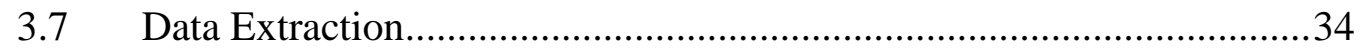

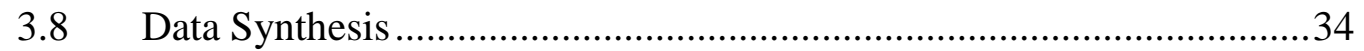

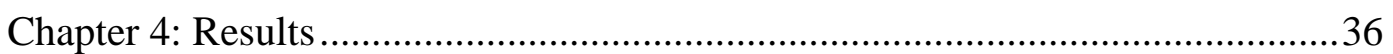

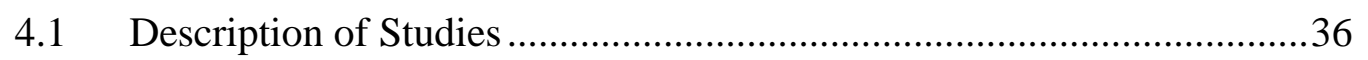

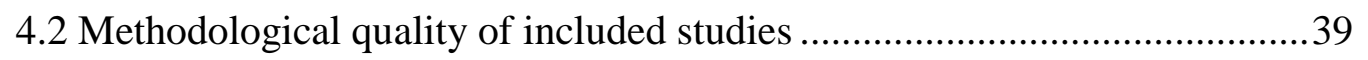

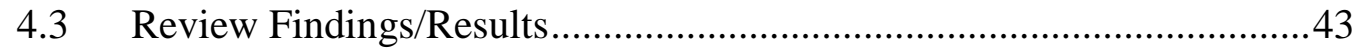

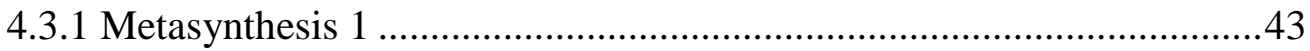

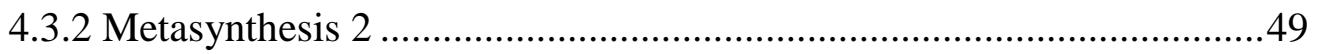

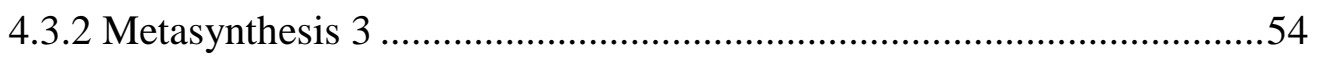




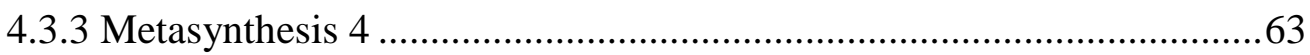

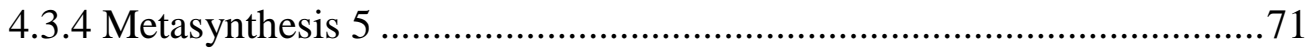

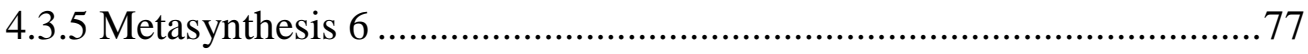

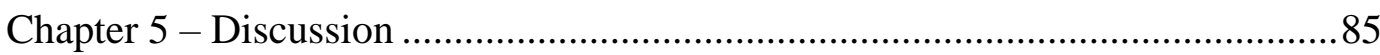

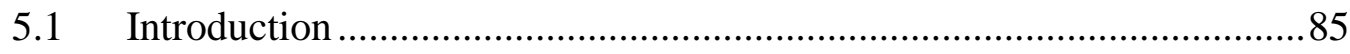

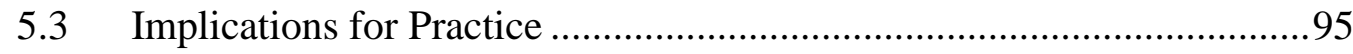

$5.4 \quad$ Implications for Future Research ................................................... 97

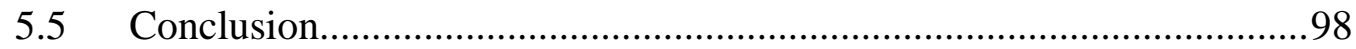

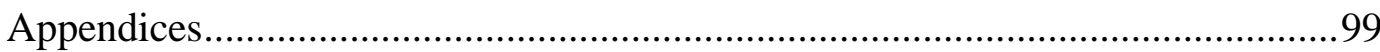

Appendix I: Validation Tool for Inclusion Criteria ...................100

Appendix II: Critical Appraisal Instrument ...............................101

Appendix III: Data Extraction Instrument .................................102

Appendix IV: Detailed Search Strategy ........................................103

Appendix V: Excluded Studies ..........................................................109

Appendix VI: Categories for metasynthesis ..........................................110

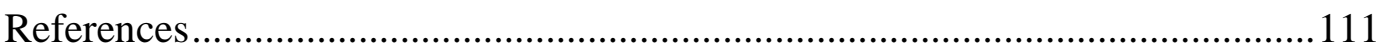




\section{Statement of Originality}

I, Mary-Anne Ramis certify that this work is original and does not contain any material that has been accepted for the award of any other degree or diploma in any other university or tertiary institution. To the best of my knowledge and belief, it contains no material previously published or written by any other person, except where due reference has been made in the text.

I give consent for this copy of my thesis, when deposited in the University Library, to be available for loan and photocopying.

Signed:

Date: 


\section{Acknowledgements}

Through my time as a student, I have had the opportunity to read many Acknowledgement pages from other theses and have found them to be informative, interesting and often, inspiring. Now that it is my turn I feel a sense of responsibility to do the same.

So firstly, I would like to acknowledge the Royal College of Nursing Australia for awarding me a scholarship to assist with this study. The funds were vital for my trips to research schools in Adelaide and for other practical concerns which are part of the higher degree process, e.g: printing, stationary, text books. It must be mentioned however that the College had no input into the study.

I would sincerely like to thank my supervisor from the Joanna Briggs Institute, University of Adelaide, Professor Alan Pearson for his guidance and support during the course of this study. I am very grateful for his advice throughout this journey.

To my supervisor in Brisbane, Dr Chuing-Jung (Jo) Wu, I express my very deepest gratitude for your support and encouragement and for always being able to steer me in the right direction when I seemed a bit lost. You have been a great friend to me during this process as well as a colleague and supervisor and I really value your wisdom and patience. Thank you also to Professor Anne Chang for introducing me to systematic reviews and for all the support you gave me during my time at the Nursing Research Centre in Brisbane. 
I would like to acknowledge and thank the staff at the Joanna Briggs Institute as well for their support and assistance when I needed it. Special thanks to Saralouise Jones and Ed Aromataris for assisting with my protocol/report and my CREMS and QARI questions. I would also like to thank Craig Lockwood for his knowledge and insight and for listening to my 'not-very-articulate' moments! To Gail Whitelock, thank you for all your help with the appraisal process and for your friendship throughout this course. I always looked forward to catching up with you in Adelaide and I wish you all the best for your degree also.

Personally, I would not have been able to complete this degree without the support and encouragement from my amazing husband, Daniel and ever inspiring son, Jacob. They have been beside me through some great adventures and some not-so-great ones and they constantly underestimate how their love and support has helped me. I am so extremely grateful to my two boys and hope that I have in some way shown Jacob that you are never too old to keep learning. Some say that knowledge is a gift but I believe the true gift is to just have the opportunity to learn and often this only comes about by having special people beside you to support and encourage you along the way.

The completion of this thesis coincides with another milestone in my life November 2012 will be my 'five-year cancer survival' milestone. I know that at that time I will become an official healthcare statistic and I can honestly say that I feel I am a living example of evidence-based healthcare (both quantitative and qualitative!). I believe very strongly in the process of improving healthcare and know that without the devoted people involved in all aspects of research and 
clinical work I would not be alive to have had the opportunity to complete this degree. I realize this page may not be read by all those who have played a part in my 'other' journey but I feel that without acknowledging them I would be taking for granted something that I strive to cherish every day. So thank you to Simon and David and to all the nurses, doctors and researchers whose work is based on improving patient care and helped to give me a second chance at the 'game of life'! 


\begin{abstract}
"Neither common sense nor science can proceed without departing from the strict consideration of what is actual in experience."
\end{abstract}

Alfred North Whitehead (1861-1947) (as cited by
Schuetz, 1953, p. 1) 


\section{Chapter 1: Introduction}

\subsection{Context of the Review}

Shortages of health care practitioners and higher patient acuity have placed pressure on acute care health systems across the globe. Demand for healthcare services will continue to rise, due to an ageing population, increased prevalence of chronic disease, advances in medical technology and changes in public expectations of health care systems (Buchan, 2000; Holloway, Baker, \& Lumby, 2009). The nursing profession globally, has evolved to try to address these needs, through the implementation of many new and innovative nursing roles, many of which have fallen under the umbrella of advanced nursing practice. There is an abundance of literature supporting the idea that advanced practice nurse (APN) roles developed as a result of economic, societal and political changes in healthcare delivery (Hanson \& Hamric, 2003; Ketefian, Redman, Hanucharurnkul, Masterson, \& Neves, 2001; Mantzoukas \& Watkinson, 2007). There is also literature that supports advanced practice roles as contributing to reducing inpatient length of stay (Wong et al, 2005) and consequent hospital costs (Newhouse et al., 2011), as well as providing a potential recruitment strategy to encourage nurses to stay within the profession (Nooney, Unruh, \& Yore, 2010). However, despite these potential benefits, ambiguity and confusion over APN roles and titles is still prevalent in some contexts, hindering consistent and effective utilisation of these experienced nurses (Daly \& Carnwell, 2003).

Historically, the APN role can be traced back to the early part of the 20th century, with American nursing establishing the Certified Nurse Midwife and Nurse 
Anaesthetist roles, however these roles were only added under the umbrella term of advanced practice nursing in the 1990's (Ketefian et al., 2001). Definition of roles and debate in the USA over blending the roles of CNS and NP has been the focus of much of the North American and Canadian literature over the last decade (Di Censo, 2008; Hanson \& Hamric, 2003; Mick \& Ackerman, 2002). In 2001, The International Council of Nurses (ICN) defined an Advanced Practice Nurse as,
"a registered nurse who has acquired the expert knowledge base, complex decision making skills and clinical competencies for expanded practice, the characteristics of which are shaped by the context and/or country in which s/he is credentialed to practice. A Master's degree is recommended for entry level." (International Council of Nurses, 2001)

This definition is very broad; allowing individual countries to contextualise APN roles to meet their own needs. Research has identified a worldwide proliferation of new nursing roles with a 2010 international survey of 32 countries (including Australia), identifying 13 different nursing titles classified as advanced practice roles. The study also highlighted an unexpected increase in the number of hospital based nurse practitioners and APNs (Pulcini, Jelic, Gul, \& Loke, 2010).

As defined by the International Council of Nurses above, the context and country within which an APN practices will play an important part in shaping individual characteristics of an APN role (International Council of Nurses, 2001). The pace with which any country develops advanced practice roles is dependent on social, 
economic, and cultural factors (Sheer \& Wong, 2008) and ironically some countries which are experiencing difficulties in providing basic health care, would benefit most from APN roles however they are severely lacking the necessary resources to educate nurses to take up these roles (Buchan \& Aiken, 2008; Sheer \& Wong, 2008)

There is a vast amount of international literature which, although agreeing on the need for APN roles, simultaneously debates and discusses the difficulties with nomenclature, definition and subsequent implementation of such roles (BryantLukosius, 2004; MacDonald, Herbert, \& Thibeault, 2006; Mantzoukas \& Watkinson, 2007). A systematic review undertaken by Lloyd Jones in 2005 identified barriers and facilitators to APN role development and effective practice, internationally. The results of the Lloyd Jones' (2005) review indicated that relationships with other staff, along with role definition and role objectives were major influences in the success or otherwise of an APN role. The practitioner's personal characteristics and previous experiences were also seen as influential both positively and negatively - to fulfilment of the role, however as this was not the main focus of the review these factors were not analysed in depth. The review identified the difficulty of synthesising research on different roles and on nurses with different levels of experience with recommendations for further research to compare specific roles and/or contexts (Lloyd Jones, 2005).

One recurring theme within the APN literature, is the need to identify commonalities or "generic features" (Mantzoukas \& Watkinson, 2007) within advanced practice roles. The ICN definition above refers to the characteristics of 
the APN role as being determined by the "context and/or country" (International Council of Nurses, 2001) within which the APN practices. Although there have been some attempts over the years to compare roles between countries, and previous acknowledgment that Australian nursing has been influenced by the ideas of North America (Coombs, Chaboyer, \& Sole, 2007; Duffield, Gardner, Chang, \& Catling-Paull, 2009), Australia has been characterised by Offredy (2000) as having "sparsely distributed populations and considerable geographical and social diversity" (p.275) which provides a unique aspect to the development of health care delivery services (Offredy, 2000). The aim of this review therefore is to assess the qualitative research on advanced practice nurses within the specific context of Australian acute care settings using a systematic, evidence based approach, to enable a greater understanding of the experience of APN practice.

\subsection{Structure of this Thesis}

This thesis comprises five chapters. This introduction chapter will provide the reader with an introduction to the study from a global perspective and outline the structure of the thesis.

The second chapter will provide the background of the phenomenon of advanced practice within Australia and identify the research question which this review aims to answer. An overview of qualitative synthesis and the methodological basis used for the review will follow and the chapter will conclude with an overview of the nature and potential value of context- specific systematic reviews. 
Chapter three will discuss the study design and methods used for the review, with specific information provided on the search strategy, critical appraisal process and data extraction methods used.

Chapter four will present the results of the review, including detailed information on the studies selected as well as the synthesised findings following from the review process.

The fifth chapter will include an in-depth discussion and analysis of the results of the review. Conclusions will be presented along with implications for practice and further research. Limitations to the study will also be included in the final chapter. 


\section{Chapter 2: Background}

\subsection{The phenomenon of advanced practice nursing in Australian Acute care settings}

Currently within Australia, there are three main advanced roles within the acute care system; namely the Clinical Nurse Consultant (CNC), the Nurse Practitioner (NP) and the Clinical Nurse Specialist (CNS). In some states of Australia the CNS role is not considered an advanced practice role, rather a specialty role (Pearson, Lockwood, Florence, \& Thomas, 2008). In the United States of America, psychiatric clinical nurse specialists are an example of one CNS role that has been recognised as an advanced practice role since the 1950's (although there is some current discourse on the potential evolution of this role to a Nurse Practitioner role (Jones \& Minarik, 2012)). Discussion on the similarities and differences between clinical nurse specialist roles and other advanced practice roles in nursing is ongoing, nationally and internationally and will be discussed further within this thesis. An overview of the development of the main acute care advanced practice roles implemented in Australia will be discussed first, followed by an elaboration on the phenomenon of advanced practice nursing within Australia and the exploration of the concept of context and its relationship to the ontological discussion.

The Clinical Nurse Consultant (CNC) role was first recognised in Australia in the state of New South Wales in 1986 (O'Baugh, Wilkes, Vaughan, \& O'Donohue, 2007). At this time each individual state of Australia was responsible for regulating nursing practice and conditions and role nomenclature varied between the states. An early study undertaken by Appel, Malcolm and Nahas in 1990/1991 
identified the $\mathrm{CNC}$ role as being applicable to hospital and/or community practice and as being developed according to organisational needs, providing an element of freedom for CNCs to evolve (Appel, Malcolm, \& Nahas, 1996), as the organisation's needs evolved. In 1990, the role was originally defined as:

"A registered nurse appointed as such to a position approved by the [New South Wales] Department [of Health] and has had at least five post-basic registration experience and who has in addition approved post-basic nursing qualifications relevant to the field in which he/she is appointed, or such other qualifications or experience deemed appropriate by the Department” (NSW Health, 1990, as cited in Appel, Malcolm \& Nahas, 1996).

As the CNC role was adopted throughout other states of Australia, it was at times, mistakenly, interchanged with the title of Clinical Nurse Specialist (CNS) (O'Baugh et al., 2007); possibly due to similarity in American nomenclature, but also possibly as a result of lack of clarification and definition of the roles between the states of Australia. In some states of Australia the CNC may progress through different grades of practice as defined by the governing body for that area, for example, in New South Wales the CNC may be known as a grade 1, 2 or $3 \mathrm{CNC}$ with each higher grade requiring more experience and qualifications as set out by the award for that area (NSW Health, 2005). It is important to note here that the private healthcare sector award may be different to the public healthcare sector, despite use of the same terminology, adding to the overall, national confusion. 
The CNC role is complex (Bloomer \& Cross, 2011; Vaughan, Wilkes, O'Baugh, \& O'Donohue, 2005) and those in the role are expected to demonstrate skills and qualities that span across domains of education, research, leadership and consultancy, according to state award definitions (Bloomer \& Cross, 2011; NSW Health, 2005; Vaughan et al., 2005). However a nationally agreed definition of the role is still absent from the literature, and to date, the $\mathrm{CNC}$ role is seen as a title adopted by an organisation, unlike a role such as the Nurse Practitioner which has been regulated by legislation, academic qualification and competency (Duffield, Chang, Fry, \& Stasa, 2011).

The Clinical Nurse Specialist (CNS) role was implemented to provide nurses with an avenue for promotion according to their clinical expertise, potentially enhancing retention of specialised nurses who wished to stay at the patient's bedside (Appel et al., 1996; Elsom, Happell, \& Manias, 2006). Although both the $\mathrm{CNC}$ and $\mathrm{CNS}$ roles utilise concepts of expanded practice, it is argued within the literature that the word 'specialist' in the CNS title does not equate to the definition of 'advanced' practice, which implies a higher and broader level of practice, beyond specialisation (Pearson \& Peels, 2002). The terms advanced, expanded and extended are among some of the terminology used to discuss nursing practice and have been the focus of discussion nationally and internationally. Within Australian acute hospitals, many nursing positions are still defined by the specialised unit, department or field in which the nurse works, such as the intensive care unit or the emergency department. This adds to the confusion on nursing titles as one may be adapted to an individual within an organisation, rather than being a nationally accepted and professionally 
standardised role (Duffield et al., 2011). The complexities and inconsistencies of terminology in Australian nursing have been the focus for other research papers (Duffield et al., 2011; Gardner, Chang, \& Duffield, 2007) and consequently will not be the main focus of this review.

The element of specialisation was the subject of a paper by Dr Marie Heartfield (2006), which reported on the confusion surrounding terminology in advanced practice. When introducing a section of the paper, Dr Heartfield writes:

"Readers are forewarned about difficulties in this section to effectively isolate and present clear definitions of the nominated terms. The discussion starts with generalist as a broad and perhaps 'first' or 'beginning' place, but from here there is no apparent order of progression in which to sequentially examine these terms." (Heartfield, 2006, p. 8)

The paper presented a clear need for accepted definitions of terms related to advanced practice from an industry and government perspective rather than an academic discussion. It also identified the fragmented approach to nursing structures throughout the country, a situation that will continue to evolve with the recent creation of a national health practitioner regulation association. Australian nursing has historically been divided between each state with individual nursing boards and governance structures resulting in state-specific approaches to nursing structures. This has allowed a greater organisational influence on nursing roles, rather than congruence within the profession (Duffield et al., 2011). In 2010 a 
national regulation system was introduced to provide a more consistent approach, not only to nursing, but all health care providers.

The Royal College of Nursing Australia (RCNA) defined advanced nursing practice in 2006, as,

"A level of nursing practice that utilises extended and expanded skills, experience and knowledge in assessment, diagnosis, planning, implementation and evaluation of the care required. An advanced practice nurse is a registered nurse who has acquired the expert knowledge base, complex decision-making skills and clinical competencies for expanded practice, the features of which are shaped by the context of the health service in which the practice is based." (Royal College of Nursing Australia, 2006, p. 1)

Their position statement goes on to identify advanced practice as the basis for the Nurse Practitioner (NP) role in conjunction with specific legislation regulation; as mentioned above, the nurse practitioner role has now been regulated and authorised throughout the country (Australian Nursing and Midwifery Council, 2004). The statement also suggests that educational preparation for the APN is based on competency assessment for functioning at an "advanced level in either a generalist or specialist capacity" (Royal College of Nursing Australia, 2006, p. 2).

An evidenced based framework consultative paper for advanced practice roles for nursing and midwifery was developed in South Australia in 2008 to guide the 
development of advanced practice roles in that state (Pearson et al., 2008). The framework was developed from an extensive literature review of national and international sources and identified that most publications on advanced practice focused on concepts of role expansion and extension as well as the myriad of titles associated with advanced practice. The final document provided a solid platform for advanced practice role development in South Australia, but was not aimed at investigating in-depth, the core concepts or generic features of the nurses working within these roles. The framework endorsed the 'clinical practice consultant role (also known as clinical nurse consultant)' and nurse practitioner role as "legitimate advanced practice roles" (Pearson et al., 2008, p. 7) but not the clinical nurse specialist role, as it defines a nurse specialist role as one who has "acquired advanced knowledge and formal qualifications sufficient to authorise practice as a specialist with advanced expertise" (Pearson et al., 2008, p. 10), while the advanced practice nurse "exhibits expansion and extension of the...role in an area of specialisation that is more complex, informed and "expert" than generic, entrylevel practice or specialist practice" (Pearson et al., 2008, p. 10). One of the synthesised findings in the paper was that advanced practice nursing roles will have a specialist focus but that their practice is extended and expanded beyond this specialty. Another finding that is frequently discussed in other Australian nursing literature, is the call for a clear, unified definition of advanced practice (Gardner et al., 2007; Pearson et al., 2008).

The titles of nurse practitioner and advanced practice nurse are often used mistakenly, interchangeably (Elsom et al., 2006) as too are the terms expert, advanced and specialist nurse (Currie \& Watterson, 2009; Jamieson \& Williams, 
2002; Por, 2008). However, one of the agreed characteristics of any APN is that they have the ability to provide a higher level of care to a patient population with complex and/or unpredictable health care needs (Bryant-Lukosius, 2004). When caring for patients with high acuity, an APN must utilise skills such critical thinking, clinical judgement and leadership. Analysing the experience of advanced practice nurses within a similar context may help to obtain a deeper understanding of how these nurses manage the complexities of their role within their area of practice. It is important to revisit here that both the RCNA and the ICN refer to context of practice as shaping APN characteristics; this is one of the concepts that will be discussed in this review.

There is other ongoing Australian research discussing different aspects of advanced practice roles within acute care settings (Gardner et al., 2007) and it is important to note here that this review is not aimed at defining role characteristics; it is focused on interpreting the available evidence to illuminate the lived experience of the described population and allow the nurses' voice to be documented. The literature on nursing experience, frequently infers clinical experience (Arbon, 2004). Clinical experience plays a crucial role in a nurse's career development, however there is limited literature acknowledging the impact of other types of experience on the nurses' growth and understanding of their role. As discussed by Arbon (2004) clinical experience adds to the knowledge and skill set of a nurse and accumulates over time, creating the basis for a nurse to evolve toward the level of expert. However clinical experience or expertise is often discussed relative to a particular context or field of practice. The RCNA (2006) definition of advanced practice reinforces this by stating that the nurses "expert 
knowledge base is shaped by the context within which the nurse practices" (Royal College of Nursing Australia, 2006, p. 1), which would seemingly equate to clinical experience within a specific area of practice. This may be more obvious in the acute care setting but to explore this concept further requires looking at 'freeflowing' evidence from the nurses themselves to obtain a perspective on what their experience incorporates within an Australian acute care setting.

\subsection{Review question}

In his paper on Clinical Nurse Consultants, Allan Walters (1996) suggested, "If advanced practice roles are to continue to develop, it is important that research is conducted to understand the fundamental dimensions of advanced-nursing practice" (p.9). Since his paper was published there have been many further studies on aspects of advanced practice, however a systematic review on the qualitative evidence of APN experiences in acute care settings, has not been

undertaken to date. Reviewing the context-specific qualitative evidence may identify situational and contextual data that will enable deeper understanding of what it means to be an APN in an Australian acute care setting as well as identify some of the "fundamental dimensions" as discussed by Walters (1996).

The aim of this review therefore, was to examine qualitative evidence regarding the field of advanced practice within Australian acute care settings only.

More specifically, the question to be answered by this review is:

What is the experience of being an advanced practice nurse in an Australian acute care setting? 


\subsection{Research Aim}

The aim of this review is to assess the available qualitative research on advanced practice nurses within the context of Australian acute care settings, using a systematic, evidence based approach, to uncover information pertaining to the experience of APN practice, and deepen our understanding of advanced practice nurses. 


\section{Chapter 3: Methods}

\subsection{Overview of the science of qualitative evidence synthesis}

Historically, the traditional positivistic paradigm of scientific enquiry provided quantitative evidence on the effectiveness of health care interventions and as such became the initial basis for the evidence based health care movement, through changing practice according to best available evidence (Pope, 2003). The randomised controlled trial was seen as the 'gold standard' of quantitative research and evidence, in its broadest sense was seen as the product of a scientific study. Similar to how the term is used in the legal system, evidence was related to truth, belief and rationality (Morse, Swanson, \& Kuzel, 2001). Synthesising results from well conducted randomised controlled trials was seen as the pinnacle of the evidence hierarchy (Dixon-Woods et al., 2006; Morse et al., 2001).

The notable rise of qualitative research undertaken through the late 1990's challenged the evidence based movement as it demonstrated a field of inquiry where scientific knowledge alone was not enough to answer complex questions being raised in areas such as health promotion, chronic illness and ethical issues arising from new technologies (Sandelowski \& Barroso, 2007). Questions on understanding, meaningfulness and feasibility of health issues were increasing and qualitative research methods were able to assist with finding more appropriate answers as well as allowing a deeper understanding of the issues, as they took into account factors such as context and cultural or social variables. 
Throughout this same time period, qualitative research became increasingly important in informing health care policy, planning and delivery as it provided a deeper understanding of the meaning of how individuals, communities or even health care workers perceived their health or made decisions relating to health. As qualitative research became more paramount, endeavours to improve validity and reliability and discussions on qualitative research findings as evidence, were heightened (Dixon-Woods et al., 2006).

The concept of synthesising qualitative evidence findings is based on the premise that one single primary research study is not enough to guide practice and flows from the desire to provide best evidence, along similar principles as for quantitative evidence. More specifically however, qualitative research synthesis can be thought of as a systematic, interpretive process aimed at reviewing and integrating findings of qualitative studies (Pearson, Wiechula, Court, \& Lockwood, 2005; Sandelowski \& Barroso, 2007). Questions as to whether it is appropriate or feasible to synthesise qualitative findings are still debated among researchers. Some believe the concept of trying to quantify qualitative findings is disparate to the holistic concept of qualitative research, in that it is trying to apply similar boundaries as for quantitative enquiry to conceptualise something that should be free-flowing and open to interpretation. At the other end of the spectrum, supporters of qualitative synthesis believe that the process is essential to provide evidence, and have consequently focused on criteria and strategies to improve the quality and value of such an inquiry (Dixon-Woods et al., 2006; Sandelowski \& Barroso, 2007). The discourse on qualitative evidence synthesis is ongoing and many authors have debated the merits and critiques of the process. 
The supporting structures for the method of qualitative synthesis used in this review are discussed below.

\subsection{Methodological basis for chosen approach to synthesis}

This systematic review followed the Joanna Briggs Institute (JBI) review method for qualitative synthesis and as such adhered to a structured process to derive synthesised findings from the included studies. One of the mains goals of this approach is to acknowledge the importance of embracing different types of authentic and valid evidence, incorporating "the context in which the care is delivered; client preference; and the professional judgement of the health professional" (Pearson et al., 2005, p. 214) to achieve improved healthcare delivery. Qualitative evidence synthesis is an emerging field of research and the JBI approach is an appropriate methodology for this review as it supports the use of multiple methods to synthesise qualitative findings; the main methods being integrative/aggregative synthesis or interpretive synthesis. The acceptance of allowing context to inform the decision making process also enhances the choice of approach for the review.

The process for synthesis must be transparent and systematic and follows the structure as outlined in this thesis. Specifically;

- Developing a rigorous protocol with an explicit research question

- Clearly stating inclusion and exclusion criteria

- Including a detailed search strategy aiming to find all relevant studies 
- Critically appraising studies meeting the inclusion criteria

- Extracting data from the primary studies regarding participants, phenomena of interest, setting and key findings,

- Pooling of findings of two or more studies. (Pearson, 2004)

It should be noted here that the protocol for this review was developed, reviewed and presented to an expert panel in August 2011 and was accepted by a qualified panel as meeting the standard required to continue.

Qualitative metasynthesis as conducted for this review is an interpretative integration of qualitative findings that may have come from phenomenological, ethnographic or grounded theory studies (Sandelowski \& Barroso, 2007). It is an artistic process of crafting together the findings from primary qualitative studies to create a report based on the findings as a whole, with the goal of being able to provide a "more plausible, coherent, complete and useful construction" (Paterson, Thorne, Canam, \& Jillings, 2001, p. 110) of the phenomena being studied.

The phenomena as studied in this review, is the experience of being an advanced practice nurse, and although the method of interpretive synthesis for the review would have accepted qualitative findings from ethnographic and/or grounded theory studies, had they met the inclusion criteria, studies identified from the search strategy and included in the review were all based on phenomenological principles. 
Phenomenological research is aimed at understanding the nature of ours or another's experience (Cohen, Kahn, \& Steeves, 2000; Van Manen, 1990). While it is not the aim of this thesis to delve deeply into the views of the great phenomenological or hermeneutic philosophers, a very brief summary of the evolvement of interpretive analysis may assist in situating the context of this review.

The philosophical underpinnings of phenomenological research can be found in the writings of (among others) Edmund Husserl (1859-1938) and Martin Heidegger (1888-1976). Husserl's influence on phenomenology was the concept of being able to 'bracket' ones assumptions to analyse an experience from a more objective, or even scientific viewpoint. Heidegger, although being a student of Husserl, explored the concept of 'being' and believed that to understand an experience, one must examine it from the inside. Both philosophers contributed to the notion of hermeneutic philosophy as we know it today, that is, the study of interpreting lives and/or experiences and how people attribute meaning to what they know (Cohen et al., 2000).

One of Heidegger's students, Hans-Georg Gadamer (1900-2002), took the study of hermeneutics further and suggested that through the process of interpretation, we are deepening our understanding of what we already know and hold to be true; that is, building on the framework of our current beliefs, prejudices and biases, to obtain a deeper, richer level of understanding (Cohen et al., 2000). Gadamer (1986) also suggested that in the process of interpreting we may be achieving two things - "pointing to something and pointing out the meaning of something 
(p.68)." He explains this further, whereby the first process "is not a reading in of some meaning, but clearly a revealing of what the thing itself already points to....We attempt to interpret that which at the same time conceals itself. (Gadamer, 1986, p. 68; also cited in van Manen, 1990, p.26).

These statements may be aligned with the process for this review, in that while synthesising findings from the included reports we are not only pointing to the findings within each report, but through using the JBI framework for metasynthesis the goal is to thoughtfully craft and identify a deeper, perhaps previously unrevealed meaning.

\subsection{Context-specific review}

Context has been defined by McCormack et al, (2002) in reference to healthcare, as "the setting in which practice takes place" (p. 94). Although this may be seen as a simplistic definition, their paper explored the concept of context and reported on the findings of a thorough literature search, including seminal and current texts, to describe context further as a complex concept influenced by many factors including culture, leadership and evaluation processes undertaken within a particular setting. More specifically, they suggest that factors including organisational systems, decision making processes and relationships among staff all contribute toward a context of practice. They proposed that through understanding context of practice, we may be able to understand more fully, the constantly changing nature of healthcare practice and conclude that context is a significant factor influencing research utilisation, a concept supported by other 
authors also (Dopson, Fitzgerald, \& Ferlie, 2008; McCormack et al., 2002; Scott, Estabrooks, Allen, \& Pollock, 2008).

The definitions of advanced practice from both the ICN and RCNA include reference to the context within which the nurse practices. However, to date no systematic review has been conducted on this topic with a specific country context as primary inclusion criteria. It may be argued that one of the reasons confusion is still apparent within some areas of advanced practice, is due to the continued attempt to compare research from different countries and contexts. Limiting the inclusion criteria to a specific context may be seen by some as a limitation to the review as it narrows the amount of research analysed, however in order to make an accurate synthesis, and one relevant to Australian healthcare, this limitation may actually be vitally important to support the discussion on advanced practice in Australia. Although findings may not transferable to other countries, the process for the review may be transferable so that other countries may be able to examine their own situation within their own context.

Context-specific qualitative systematic reviews have been undertaken on other topics, including caregiver's experience of looking after persons with HIV/AIDS in Africa (McInerney \& Brysiewicz, 2009) and Hannes \& Harden (2012) recently published a paper on their context-specific approach to reviewing qualitative evidence on obstacles to implementing evidence based practice in a Belgian healthcare system. The paper by Hannes \& Harden (2012) goes on to discuss and compare the features of a multi-context review against a context-specific review. The authors suggest that if the findings of a metasynthesis are aimed at informing 
local policy or local practitioners then a context-specific approach would be more appropriate. They suggest that the key features of such a review should comprise:

“...the use of a selective search with a focus on studies (both published and unpublished) that address a similar geographical, socio-cultural, political, historical, economical, health care, linguistic, or other context relevant to the review and as such provide lines of actions or theories that are sensitive to a particular setting. They may or may not take a national or local perspective and provide advice and suggestions that are highly relevant to some stakeholders, however, most likely less transferable to other settings." (Hannes \& Harden, 2012, p. 273)

These features are directly applicable to this review, in that it addresses the national Australian nursing context and results will inform that same context. Transferability of the findings may be limited however, if a similar review was to be conducted in other contexts, then the findings may be comparable.

\subsection{Criteria for Considering Studies for this Review}

\subsubsection{Types of Studies}

This review considered interpretive studies that drew on the experience of being an advanced practice registered nurse in Australian acute care settings and included designs such as phenomenology, grounded theory and ethnography. 
As this review was focused on describing the experience of the nurses from their own voice it included studies specifically providing rich data from nurses themselves, reported in an open and non-confined manner.

\subsubsection{Types of Participants}

This review considered publications of qualitative studies on registered nurses reported as working in advanced practice roles in acute care settings throughout Australia. Due to the ambiguity in nomenclature, different titles of APN were considered, including but not limited to clinical nurse consultant, nurse practitioner clinical nurse specialist and expert nurse.

Studies on advanced practice registered nurses working in roles within acute, hospital or tertiary care centres were the focus of this review, including those that specify different units within the acute setting, such as intensive care and critical care units as well as hospital emergency departments. Advanced practice registered nurses working in specialty fields, such as mental health, were included only if their practice setting was specified as acute care or hospital. However, studies that were undertaken in primary care, transitional care or aged care settings were excluded. Midwifery practice was not included in this review.

\subsubsection{Phenomena of Interest}

The phenomena of interest for this review was the experience of being an advanced practice registered nurse working in an Australian acute care setting, as reported by the nurses themselves. This allowed for inclusion of patient care 
related experiences and experiences involving the organisation or context of practice.

\subsubsection{Context}

The context for this review was acute care settings within Australian rural and/or urban hospitals or tertiary care centres.

\subsection{Search Strategy}

The search strategy aimed to find both published and unpublished studies. A three-step search strategy was utilised in each component of this review. An initial search of PubMed and CINAHL was undertaken followed by analysis of the text words contained in titles and abstracts, and of the index terms used to describe the article. A second search using all identified keywords and index terms was then undertaken across all included databases. Thirdly, the reference lists of all identified reports and articles were searched for additional studies.

Medline trends showed publications on the topic of advanced practice increased significantly from 1992; therefore a date limit was set to include publications from 1990 to October 2011. This date limit of 1990 was also been used in a recently published systematic review on quantitative evidence of patient outcomes of advanced practice registered nurses (Newhouse et al., 2011). English only studies were included due to limited resources available for translation and also as English is the predominant language spoken within Australia. The following databases and websites were searched: 
EMBASE

SCOPUS

Informit

PsycINFO

Nursing Consult

Academic Search Premier

Libraries Australia: The National Bibliographic Database

Australia/New Zealand Reference Centre

Australian Government websites:

AIHW (Australian Institute for Health and Welfare)

Department of Health and Ageing

NHMRC (National Health and Medical Research Council)

\section{Professional nursing associations:}

ANMC (Australian Nursing and Midwifery Council) publications

ANF (Australian Nursing Federation) publications

AHPRA (Australian Health Practitioners Registration Australia) publications

RCNA (Royal College of Nursing Australia)

CoNNO (Coalition of National Nursing Organisations)

\section{Australian health organisational websites:}

Australian Healthcare Reform Alliance

Australian Indigenous Health Infonet 


\section{The search for unpublished studies included:}

Australian Digital Theses

Google Scholar

Mednar

Conference Proceedings

For a full detailed search strategy please refer to Appendix 1.

Prior to critical appraisal a validation tool was created to ensure the selected papers did meet the inclusion criteria and were appropriate to progress to the appraisal process (Appendix II).

\subsection{Assessment of Methodological Quality/ Critical Appraisal}

Qualitative papers selected for retrieval were assessed by two independent reviewers for methodological validity prior to inclusion in the review using standardised critical appraisal instruments from the Joanna Briggs Institute Qualitative Assessment and Review Instrument (JBI-QARI) (Appendix III). A third reviewer was asked to review papers where there were differing appraisal scores or disagreement between the first two reviewers.

The purpose of appraisal is to analyse the strengths and weaknesses of the paper under analysis. The JBI-QARI appraisal tool comprises 10 questions which ask the appraiser to classify findings as 'yes', 'no', 'unclear' or 'not applicable'. One of the main concepts in the appraisal process is the presence of congruence, more specifically congruence between the philosophical perspective and research 
methodology; congruence between research methodology and research question or objectives; congruence between the research methodology and data collection methods and congruence between chosen methodology and reporting of results.

This congruency was deemed to form the essential components for this review. 'Yes' scores for questions 1-5 and question 8 on the appraisal tool - "Are participants and their voices adequately represented?" - were deemed to hold the greatest weight for selection into this review. Question 10 was also weighted heavily for appraisal as this question focused on the interpretation of results. It was imperative for this review that the results and the qualitative data were represented from the nurses' voice.

\subsection{Data Extraction}

Qualitative data was extracted from included papers using the standardised data extraction tool from the Joanna Briggs Institute Qualitative Assessment and Review Instrument JBI-QARI (Appendix IV). The data extracted included specific details about the populations, setting, study methods and the phenomena of interest relative to the review question.

\subsection{Data Synthesis}

Qualitative research findings were pooled using the Qualitative Assessment and Review Instrument (JBI-QARI). This involved aggregation or synthesis of findings to generate a set of statements that represented that aggregation, through assembling the findings (Level 1 findings) rated according to their quality, and 
categorisation of these findings on the basis of similarity in meaning (Level 2 findings). These categories were then subjected to a metasynthesis in order to produce a single comprehensive set of synthesised findings (Level 3 findings) that can be used as a basis for evidence-based practice. Included findings were read and re-read for similar meanings and supporting quotes (illustrations) were extracted. Each finding was assessed a level of credibility according to the QARI module. The levels of credibility were as follows:

- Unequivocal (U) - relates to evidence beyond reasonable doubt which may include findings that are matter of fact, directly reported/observed and not open to challenge.

- Credible (C) - those that are, albeit interpretations, plausible in light of data and theoretical framework. They can be logically inferred from the data. Because the findings are interpretive they can be challenged.

- Not Supported (NS) - when neither 1 nor 2 apply and when most notably findings are not supported by the data.

There is a range of opinion and discussion over what constitutes a finding in qualitative research (Sandelowski \& Barroso, 2007). The JBI Reviewers' Manual defines findings as "conclusions reached and reported by the author of the paper, often in the form of themes, categories and metaphors (The Joanna Briggs Institute, 2008, p. 133). The JBI process also identifies and supports the use of "direct quotes, observations or statements (p.35)" that have assisted the author to reach their conclusion. This process identifies and confirms the level of association between the finding and the participants within the primary research studies (The Joanna Briggs Institute, 2008). 


\section{Chapter 4: Results}

\subsection{Description of Studies}

Following the systematic search, 1220 titles were identified. These titles were carefully screened and 154 were extracted for further analysis of their abstracts. Following analysis of the abstracts, 18 full-text papers were retrieved. After reading the full text, eight (8) papers were deemed to meet the inclusion criteria and were selected for critical appraisal. All eight papers were critically appraised by both reviewers and four of these papers were reviewed by a third reviewer as there were some differences in the appraisal scores as well as some difference in whether the papers fully met the inclusion criteria. Four studies were then agreed on for inclusion in the review however one of these papers required clarification on the setting of the study (Bloomer \& Cross, 2011). The authors of this paper were contacted via email and confirmed that the setting was not restricted to acute care and included community care, therefore the paper was excluded as not meeting the inclusion criteria.

During a university function, I was verbally informed of an unpublished dissertation (Taylor, 1999) from a postgraduate nursing student which was thought to meet the inclusion criteria. Consequently the thesis was obtained from the author and after appraisal was considered to necessitate inclusion in the review. This situation has been noted as one of the potential scenarios when conducting context-specific reviews whereby having local knowledge and networks, the availability of unpublished material may arise from personal contacts (Hannes \& Harden, 2012). As discussed in their paper during their 
searching process, one paper was retrieved through personal contact and two others through access to local government or professional organisation databases. They suggest that for their study, "these three publications would probably not have been found by a non-native reviewer" (Hannes \& Harden, 2012, p. 275). The dissertation was sent to a third reviewer to identify if it met the inclusion criteria for this review. This procedure was also followed for the current review to enhance credibility for the inclusion process, due to the manner in which the thesis was discovered.

Final results from the search strategy and appraisal process identified 4 papers for inclusion (three published studies and one unpublished dissertation) and each study was based on phenomenological and/or hermeneutic principles. The search process for the review is depicted in Figure 1. 


\section{Figure 1: Search process}

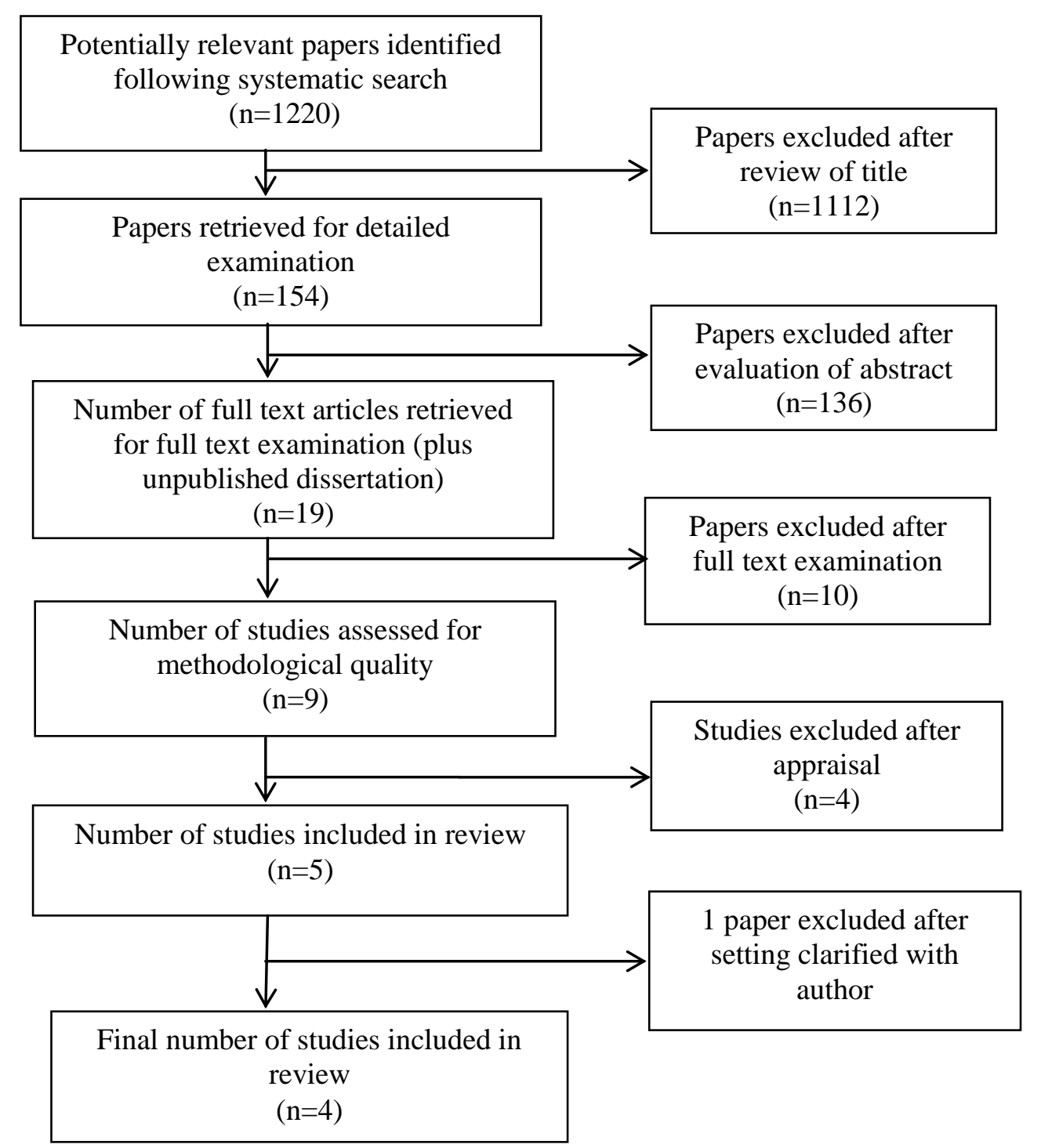

The reference lists for each paper selected for appraisal were hand searched but no new studies were found to add to the search process. 


\subsection{Methodological quality of included studies}

The methodological quality of the three published studies included in the review was comparable. All three papers were qualitative in nature, with two based on hermeneutic phenomenology principles (Borbasi, 1999; Walters, 1996). The third published paper was a qualitative study (O'Connor \& Chapman, 2008) and although it did not refer to using a phenomenological design, the data within the paper provided a rich depth of understanding of the experience of being a palliative care nurse consultant. The methodology for this paper was described as "an in-depth exploration of the palliative care nurse consultant role" (O'Connor \& Chapman, 2008, p. 152), and Van Manen's framework for thematic analysis was used to analyse the data. Two other papers included in the review used a phenomenological approach with thematic analysis based on the works of Polyani (Walters, 1996) and Van Manen (Borbasi, 1999). Each published paper identified the nurses as either advanced practice or expert nurses.

The first published paper (Walters, 1996), had a very clear and thorough report of the data collection process, which included the researcher listening, to and rereading transcripts and taped interview conversations, prior to interpreting the data. This detailed level of reporting on the research process enhances the credibility and dependability of the study, as supported by Shenton (2004) who suggests, "The processes within the study should be reported in detail, thereby enabling a future researcher to repeat the work, if not necessarily to gain the same results." (Shenton, 2004, p. 71). 
The paper by Borbasi (1999) included a comprehensive report on the varying methods of data collection. Data were collected using interviewing, journaling as well as participant observation in order to present a "...'full picture' of the world of the CNS" (Borbasi, 1999, p. 23). The author reports that in order to understand the world of the CNS, one must be immersed and participate in that same world. The rapport that was developed using these multiple data collection techniques also enhances the credibility of the study, in that it encourages a relationship with the researcher which enables participants to feel comfortable and discuss more, indepth information with the researcher. Multiple methods of data collection may be seen as one form of triangulation, where by "two or more methods are teamed in such a way that the weakness of one is compensated by the strengths of another."(Guba, 1981; Seale, 1999).

The third published paper included in the review (O'Connor \& Chapman, 2008) reported on collecting data during audio taped interviews, each of 45 minutes duration, which were analysed using Van Manen's six step process of thematic analysis. Although there was limited information on the methods of the study as compared to the other studies, the primary author did report that both authors reached agreement on the themes through "reading and re-reading the emergent themes and structuring of information through continuous dialogue" (O'Connor \& Chapman, 2008, p. 153). This technique is supported by Rice \& Ezzy (1999) as a way of identifying patterns within the data and identifying emergent themes (Rice \& Ezzy, 1999). 
The unpublished dissertation included in the review was part of a Masters award and included an interpretive study of seven orthopaedic advanced practice nurses. Individual role titles were not given for the participants, however they were all deemed to possess an expert level of specialised skill, as decided by the researcher, but supported by Benner's (1984) definition of expert nurse. This definition suggests that expert nurses are separate from their less experienced colleagues through their enhanced ability to make critical decisions by looking at a situation in parts and as a whole. They are also able to use a heightened level of intuitive ability in their practice (Benner, 1984; Taylor, 1999; McHugh, 2010). The participants in the study were interviewed individually and asked to recall an event where they believed they used advanced practice skills. Their transcripts were analysed according to Heideggarian hermeneutic phenomenology principles (Hermeneutic circle) and van Manen's (1990) framework for studying lived experience was used to thematically analyse data obtained in the interviews. A very thorough process was reported in the dissertation, with clear information on the researcher's perspective and own understandings, making it a high quality example of a phenomenological study and worthy of inclusion in this review.

A summary of the included papers is seen in Table 1. 


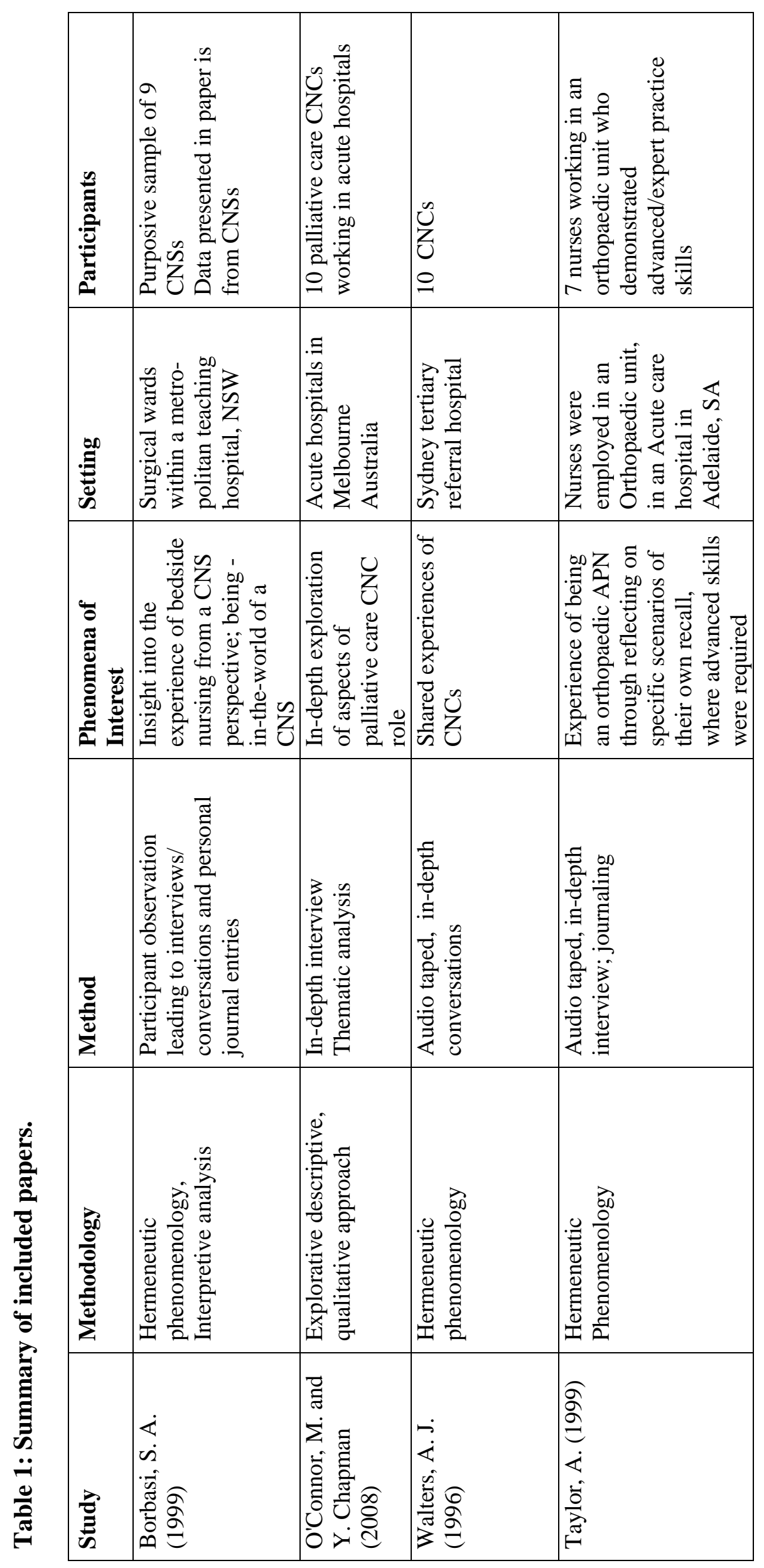




\subsection{Review Findings/Results}

Following data extraction, 216 findings were identified from the four included studies. Following further analysis these findings were condensed into 18 categories (second level findings) based on similar meanings. These categories were then further collated into a comprehensive set of 6 synthesised findings (meta-syntheses). Each metasynthesis with corresponding included findings and categories will be presented below. A list of all the categories created from the findings is included as Appendix VI.

\subsubsection{Metasynthesis 1}

Expert knowledge: Advanced practice or expert nurses working in Australian acute care settings demonstrate a broad, expert knowledge base in their practice which leads them to become an informal and/or formal educational resource for staff, patients and families. It also enables them to instruct, mentor and/or supervise junior medical and/or nursing staff when necessary, which may have a negative impact through increased workload and responsibility. Their expert knowledge is a benefit to patient care as it enables them to pick up subtle signs that may indicate potential complications. Specialty knowledge relative to their area of practice is the basis of their clinical expertise and provides the nurse with an enhanced ability to assess their patients with a specialist focus as well as a holistic approach. 
This metasynthesis was created from 2 categories with 28 findings. Illustrations from the data to support each finding are included below. Levels of credibility are also included for each finding.

Category 1 Summary - Expert knowledge: expert knowledge is required, utilised and is ongoing.

Finding 1: Expert knowledge and holistic care (C)

Illustration: 'Working with people who are ill requires that the nurse consultant provide a specialized service that focuses on a particular disease while simultaneously caring for the whole person.' (Walters, 1996 p.8)

Finding 2: Picking up on subtle and unusual signs which may indicate potential complications that inexperienced staff may oversee (U)

Illustration: "...something you wouldn't really expect". (Borbasi, 1999; p.26); "...there wasn't anything obvious at first, but she was incontinent; which was unusual...we thought something was wrong..." (Borbasi, 1999; p.26)

Finding 3: Alert to complications (C)

Illustration: '...she knows complications can occur and anticipates them.' (Borbasi, 1999; p.26)

Finding 4: Expert knowledge of symptoms (U)

Illustration: "...the patients temperature had gone up to 390 per axilla; her pulse had gone up to 140 and she was very restless and so we [read I] were querying maybe a PE [pulmonary embolus] or something...so the doctor came and felt the same about the whole situation..." (Borbasi, 1999; p.26)

Finding 5: Able to discern expert nursing care from medical care (U) 
Illustration: "...those clinics are so busy, you can well do without people coming in with problems that aren't really related to doctors anyway." (Borbasi, 1999; p.27)

Finding 6: Recognise importance and consequences of expertise (U)

Illustration: "...they're [inexperienced staff] taking risks they know nothing about, and that's not good enough. That's why we have to have senior staff - a ward that's run on junior staff is a dangerous place.” (Borbasi, 1999; p.27)

Finding 7: In-depth knowledge allows effective decision making (U)

Illustration: "I just took her straight into the dressing room, I drained it and sent a specimen off... [put] her on some antibiotics and that was it. There was a sigh of relief when all this fluid came out..." (Borbasi, 1999; p.27)

Finding 8: Expanding knowledge due to extending service to other areas (U)

Illustration: "So that had led us to the field of renal failure, cardiac failure, respiratory failure, stroke, which is a learning curve." (O’Connor, 2008; p.156)

Finding 9: Varied clinical expertise (C)

Illustration: 'Clinical expertise required being responsive in relation to management or commentary on treatment variations, family crisis management or providing insights into new care techniques.' (O’Connor, 2008; p.154)

Finding 10: Using expert knowledge to instantly assess the situation (C)

Illustration: '...immediately took charge of the situation.'(Taylor, 1999; p.61)

Finding 11: Expert assessment skills (U)

Illustration: "...and when I got there the nursing staff member was trying to maintain her airway but without supporting her spinal fusion.... (She) wasn't breathing and (she) had no carotid pulse." (Taylor, 1999; p.61) 
Finding 12: Advanced assessment skills enhance awareness of potential complications relative to specialised knowledge as well as basic life support. (U)

Illustration: "They just didn't even think about her orthopaedic injuries, they were more concerned about her airway which, yeah sure it's her primary concern, but she was breathing and she was responding." (Taylor, 1999; p.63)

Finding 13: Specialised knowledge vital for positive outcome (U)

Illustration: "...or just maybe the potential if we didn't have that orthopaedic knowledge, the potential complications is what I thought of afterwards ... we could have done more damage than good." (Taylor, 1999; p.65)

Finding 14: Expert and specific knowledge gained from clinical experience and formal education $(\mathrm{U})$

Illustration: "Not just specific orthopaedic knowledge, but also that higher level of orthopaedic knowledge that I have got as well. On the ward nurses don't necessarily do a complete orthopaedic assessment on range of motion and joint function and I have been taught how to do that in the ortho [paedic] course and also by doing this job." (Taylor, 1999; p.67)

Finding 15: Specialised knowledge (U)

Illustration: "...no-one else knew how to set up the traction at all or what ... that sort of stuff to do.” (Taylor, 1999; p.73)

Finding 16: Using specialised knowledge to suggest alternate plan of care (C)

Illustration: 'By drawing on his knowledge of the principles of traction and fracture management and previous experience, [he] suggested an alternative way of reducing the fracture.' (Taylor, 1999; p.73)

Finding 17: Drawing on previous knowledge and experiences but still learning (U) 
Illustration: "I mean the nuts and bolts of what happened is different to what I have ever been through before but it's a situation that has the same sort of stressors, the same sort of concerns and the same way of approaching it I've done quite a few times so I guess yeah ... yeah I probably learned a bit." (Taylor, 1999; p.93-94)

Finding 18: Expertise informs initial patient assessment (U)

Illustration: "... she was a frail old lady who was quite small and she was quite with it. But she'd obviously had medical problems you could tell that by looking at her. And umm, you could see her hip...And I also noticed that her upper leg was deformed, it wasn't natural alignment. Umm, and I noticed that she was in pain... "(Taylor, 1999; p.97)

Finding 19: Knowledge and skills give confidence to work beyond role (U)

Illustration: "I felt confident in a way, I mean I knew we were doing stuff that, we weren't really [slight pause] qualified or whatever - for want of a better word, to do but I knew sort of, I had the knowledge and skills so hopefully we could fix it in the end... "(Taylor, 1999; p.98)

Category 3 Summary - Education: APNs are an educational resource for their departments and spend a large amount of time educating peers, staff, patients and their families.

Finding 1: Educating and instructing junior medical staff ('telling' junior medical staff what needs to be done) (U)

Illustration: " A big part of our role is teaching doctors, because Registrars have hardly got the time....We are the ones telling them things like 'you need these 
bloods, they need this test, here fill out these forms and we will do it." (Borbasi, $1999 ;$ p.24)

Finding 2: Supervising inexperienced health professionals (U)

Illustration: "I always keep a close eye on them" (Borbasi, 1999; p.26) "They were about to pull the tube out... and there was a chance the patient would have got a pneumothorax. If I hadn't said to them, 'Oh there's no suture there'..." (Borbasi, 1999; p.26)

Finding 3: Education resource for inexperienced health professionals (U)

Illustration: “...it's a matter of educating them, but yeah, acknowledging that we work in a large teaching hospital and that you are working with interns who are just out of their training." (O’Connor, 2008; p.153)

Finding 4: Educating other health professionals (U)

Illustration: "...and then we may go through a few things with them and teach them." (O’Connor, 2008; p.153)

Finding 5: Diverse patient educational role (U)

Illustration: "The doctor may have just seen them to prescribe one or two medications or indicate that he wants me to get them off certain drugs; then it's up to me to teach the patient how to do the drug withdrawal and how to manage"(Walters, 1996; p.6)."I gave her a lot of education. She did not know anything about aseptic technique, nothing about her treatment. We started with the basics of hand washing and progressed from there..." (Walters, 1996; p.9)

Finding 6: Patient education leads to patient empowerment (U)

Illustration: "In the beginning, she didn't want anything to do with her treatment, but she knew that mastering it was the only way she was going to get home...she is coping extremely well now." (Walters, 1996; p. 9) 
Finding 7: Educating other nurses $(\mathrm{C})$

Illustration: 'Being able to directly change nursing practice involves providing educational sessions in classroom settings and working with other nurses in the clinical environment.' (Walters, 1996; p. 9)

Finding 8: Mentor $(\mathrm{C})$

Illustration: ‘...in a mentorship role.' (Walters, 1996; p. 9)

Finding 9: Educating other staff to improve care and patient outcome (C)

Illustration: '...turned what she perceived as a problem with nursing care, into an educational opportunity for the nurse responsible for delivering care to this patient.' (Taylor, 1999; p.69).

\subsubsection{Metasynthesis 2}

Spectrum of work activities: Advanced practice or expert nurses working in Australian acute care settings experience routine day-to-day activities interspersed with unpredictable events. This requires them to be flexible, adaptable and responsive. They are able to use the routine activities to their advantage; however the diversity of their role can cause them to experience the spectrum of mundane to chaotic situations within the same day. The responsive, reactive nature of their work makes it difficult for them to articulate at times, what they actually do.

This metasynthesis was created from 2 categories with 27 findings. Illustrations from the data to support each finding are included below. Levels of credibility are also included for each finding. 
Category 2 Summary - Routine daily activities: APNs experience a certain amount of routine in their daily work.

Finding 1: Finding value in simple, repetitive tasks (U)

Illustration: "...yet, we find out all these other things while we're just making their beds." (Borbasi, 1999; p.23)

Finding 2: Care planning (U)

Illustration: "...or look at how we can best care for them now that they have been given a palliative diagnosis..." (O’Connor, 2008; p.153)

Finding 3: Discharge planning (U)

Illustration: "...and of course come discharge planning." [Describing daily activities] (O’Connor, 2008; p.153)

Finding 4: Routine daily activities (C)

Illustration: 'Many participants described their daily activities as "doing a circle".' (O’Connor, 2008; p.153)

Finding 5: Regular tasks (C)

Illustration: '...obtain a medical history, perform an orthopaedic examination and assessment, and initiate discharge planning.' (Taylor, 1999; p.65)

Category 6 Summary - Multi-dimensional role: APNs work in diverse areas with varying management responsibilities and functions. They may work independently or interdependently.

Finding 1: Versatile (C)

Illustration: 'versatility to take on multiple roles' (Borbasi, 1999; p.25)

Finding 2: Conducting nursing and non-nursing roles (C) 
Illustration: '...take on multiple roles, both legitimised (unit manager) and nonlegitimised (porter, cleaner, ward clerk).' (Borbasi, 1999; p.25)

Finding 3: In the middle but with multiple functions (U)

Illustration: "...with the NUM [Nurse unit manager] at the top and the CNSs as second-line managers we are the monitors, mediators and creators of protocol in every aspect of patient care and public relations." (Borbasi, 1999; p.23)

Finding 4: Multitasking (U)

Illustration: "...do three things at once." (Borbasi, 1999; p.25)

Finding 5: Diverse role (U)

Illustration: "...it goes all the way from seeing a patient, treating them, consulting them, providing a service to that patient, the treatment options that I might do for them, all the way to being the clinical co-ordinator, the secretary, the financial controller and manager." (Walters, 1996; p.5)

Finding 6: Working in many different areas (C)

Illustration: 'Nurse consultants work in high-technology areas, outpatient clinics, specialized ward areas and diagnostic areas in hospitals and community health services' p.5 '...some nurse consultants are experts in working with people who are dying of incurable diseases.' (Walters, 1996; p.8)

Finding 7: Multiple functions and activities (U)

Illustration: "I have so many things on my plate, so many things I am involved in."(Walters, 1999; p.5) "I do a lot of things"(Walters, 1996; p.5)

Finding 8: Independent practitioner (U)

Illustration: "In my area of clinical practice, the doctors are basically quite happy to let me manage the patients by myself, and if there are any problems I usually 
just contact them; but the day-today management of the patients, that is my responsibility." (Walters, 1996; p.7)

Finding 9: Responsive (U)

Illustration: "...you go along and as things come up you've got to deal with them as you see fit at the time" (O’Connor, 2008; p.155)

Finding 10: Unpredictable (U)

Illustration: "Whatever you had planned can be so totally blown out the window by other things...often because you just don't know what you are going to find." (O’Connor, 2008; p.155)

Finding 11: Variability in role (C)

Illustration: 'There were many differences between the participants, their titles, how they worked, their remuneration.' (O'Connor, 2008; p.155)

Finding 12: Problem solver (U)

Illustration: "I come into chaos and I give some order to the chaos." (O’Connor, 2008; p.155)

Finding 13: Multi-dimensional role (C)

Illustration: "These roles include: being an advocate and assessor for both people requiring care and staff; a liaison person between staff discipline groups and between staff, patients and their relatives; a counsellor for staff, and an educator and consultant for other nurses." (O’Connor, 2008; p.153)

Finding 14: Variety (U)

Illustration: "Well I can't say our role is rigid. Every day is different" (O’Connor, 2008; p.155)

Finding 15: Broad consultancy role (U) 
Illustration: "We are asked for an opinion and it's an all-encompassing role of anywhere from symptom management to acute bereavement counselling to discharge planning..." (O’Connor, 2008; p.154-155)

Finding 16: Day-to-day uncertainty (U)

Illustration: "...as much as the unpredictability can be exhausting, that's what makes it interesting." (O’Connor, 2008; p.153)

Finding 17: Difficult to articulate experiences (U)

Illustration: "I think I find it hard to talk about my experiences because there are so many things that I do." (Walters, 1996; p.5)

Finding 18: Variation in direct-reports and line-management responsibilities (C)

Illustration: 'Some nurse consultants have no direct-line management responsibilities, acting only in an advisory capacity, whereas others have linemanagement responsibilities for clinical units'. (Walters, 1996; p.5)

Finding 19: Independent and interdependent role dimensions (U)

Illustration: "We have the independence to actually assess the patient and then do the test we think is most appropriate for that patient" (Walters, 2008; p.6)

Finding 20: Complex role description (U)

Illustration: "unfolding"; "evolving"; "well it's a complex role and it has changed over those six years." (O’Connor, 2008; p.155)

Finding 21: Management skills (U)

Illustration: “...[I] quickly found a bed for this patient (by diplomatically asking a patient awaiting discharge to vacate his bed), attempted to calm the patient because he was screaming in pain, placate the parent's anger and arranged an intern to assess the patient." (Taylor, 1999; p.78)

Finding 22: Coordinator not leader (U) 
Illustration: "As a professional with knowledge, experience in that area. Feeling confident in my interactions with the patient, with my interactions with the other staff, with the consultant and the registrar; I see myself as more of a coordinator; I don't like really to say I am a leader, but more of a coordinator. Just making sure that everything's smooth and runs according to plan." (Taylor, 1999; p.77).

\subsubsection{Metasynthesis 3}

Confidence and familiarity: Advanced practice or expert nurses working in Australian acute care settings become very familiar with their work and over time, develop confidence in their ability which enables them to make quick decisions, prioritise, and bypass the normal chain of command if necessary. The confidence they acquire in their role from this familiarity is often demonstrated intuitively or instinctively and enables them to cope with a wide range of issues; however the nurses are very mindful that they are accountable and responsible for their actions, not just to their patients, but to their colleagues, the organisation and themselves.

This metasynthesis was created from 4 categories and 44 findings. Illustrations from the data to support each finding are included below. Levels of credibility are also included for each finding.

Category 14 summary - Familiarity and clinical experience: APNs exhibit familiarity with tasks and have the ability to use their previous experience to deal with varied issues.

Finding 1: Familiarity (U) 
Illustration: "...when you see the same patients - not the same personality types obviously, but having the same sorts of surgery, same sorts of prognosis, you tend to be able to pick what they are like." (Borbasi, 1999; p.25); “ I've been through enough unexpected incidents to know what to do" (Borbasi, 1999; p.26); "You can put on two thousand pairs of TED ${ }^{\mathrm{TM}}$ [thrombo-embolic] stockings and you get to the two thousand and first pair and they seem to go on more easily and more comfortably for the patient.....It's the same for every nursing procedure." (Borbasi, 1999; p.25)

Finding 2: Wide range of experience in their field (U)

Illustration: "You have a lot of experience in the field in which you are a consultant: hands on experience, and you have dealt with a broad range of diseases, so you have the experience to deal with a broad range of issues." (Walters, 1996; p. 7)

Finding 3: Reflection as part of experience (U)

Illustration: "That's all part of - I think experience, is, about looking at the outcome in the end and seeing what you could have done differently, or what you did well." (Taylor, 1999; p.74)

Finding 4: Past experience improves confidence in assessing situations (U)

Illustration: "Umm, [pause] I guess I didn’t panic. I drew on a lot of my experience. Umm I think I assessed the situation as a whole. I thought I didn't get too focussed on one little thing." (Taylor, 1999; p.74)

Finding 5: Using previous experience (U)

Illustration: "...and it just reminded me so much of this other case of ten years ago; that required skin grafting with muscle flaps." (Taylor, 1999; p.82) 
Finding 6: Recalling previously learnt knowledge and applying it to current situations (U)

Illustration: "It's amazing, when you see it in practice how often you put twoand-two together, and it just clicks in your mind and yes I remember this and that and other things you are supposed to be looking out for, and it all came back to me." (Taylor, 1999; p.92-93)

Category 5 summary - Confidence influences practice: Confidence in their role allows APNs to make quick and effective decisions, time manage, prioritise and bypass hierarchy if required.

Finding 1: Willing to bypass usual personnel chain when necessary (U)

Illustration: "Whereas we bypassed a lot of people to get urgent treatment for that girl". (Borbasi, 1999; p.25); "...she is not afraid to transcend a number of links in the hierarchical chain of medicine in order to 'get' the people who are more competent." (Borbasi, 1999; p.25) "You can sort of intervene and get the doctors up quickly..."(Borbasi, 1999; p.25)

Finding 2: Confident with difficult tasks (U)

Illustration: "I've encountered them before...I know it can be niggly... so I knew it was going to be a problem...they [sutures] can be removed - you just have to get the stitch cutter right in there.." (Borbasi, 1999; p.25)

Finding 3: Effective ward management (U)

Illustration: "In this ward the patients don't recover by good luck, it is our good management." (Borbasi, 1999; p.23)

Finding 4: Quick response (C) 
Illustration: ' $\ldots$ when complications occur, the CNS responds decisively' (Borbasi, 1999; p. 26)

Finding 5: Decision maker (U)

Illustration: "...You make decisions then and there as a senior nurse..."(Borbasi, 1999; p.27)

Finding 6: Confidence when acting autonomously (U)

Illustration: "I wrote a letter to her GP saying: 'I drained the lymphocele'." (Borbasi, 1999; p.27)

Finding 7: Setting own high standards irrespective of medical staff (U)

Illustration: "The standards we (the senior nurses) create are what gets our patients through; not the HMO's [Hospital medical Officers] and certainly not the junior MO's [Medical Officers]” (Borbasi, 1999; p.23)

Finding 8: Adapting (U)

Illustration: "The way we handle every case is different." (O'Connor, 2008; p.155)

Finding 9: Able to prioritise and manage potentially serious incidents in succession (U)

Illustration: "Well it started quite early, it started about $10.30 \mathrm{pm} .$. one of the patients was a bit wheezy and breathless so we put oxygen on...were querying a PE...[Pulmonary embolism]...so we put more oxygen on...then a man who had had a neck dissection yesterday...from 3 to 3.30 (a.m.) his neck had blown right up...his pulse was only $60 \ldots$ his blood pressure was $60 / 30 \ldots$ they took him to theatre...then at 6 O'clock another man who hadn't like to ring us earlier in the night - said he had chest pain and he'd had it most of the night: but we were so busy he hadn't like to ring..."(Borbasi, 1999; p.26) 
Finding 10: Take control (C)

Illustration: '...immediately took charge of the situation.' (Taylor, 1999; p.61)

Finding 11: Delegation (C)

Illustration: ' ...she instructed someone to ring the emergency number.' (Taylor, 1999; p.62)

Finding 12: Mixed feelings about conscious decision to bypass normal chain of responsibility $(\mathrm{U})$

Illustration: "I felt a bit guilty...Because it's always been that nurses are not, not there to call the shots on what happens. They are not the people that make the decisions and the medical staff are responsible for that and that we should answer to them. But in this situation I wasn't answering to anybody. The nursing staff were the ones in control of the situation." (Taylor, 1999; p.64)

Finding 13: Confident nursing care (C)

Illustration: “...prepared the patient, on the basis of her findings.” (Taylor, 1999; p.66)

Finding 14: Confidence with patient assessment (U)

Illustration: "Looking at her, it is amazing how quickly you get to judge people. [laughs] You can pick off the head probably nine times out of ten, the ones you think are going to get up out of bed and progress according to plan and go home with minimal supports and that type of thing. And the ones that are probably going to need a little bit longer or extended rehab or you know that they are going to struggle at home." (Taylor, 1999; p.67)

Finding 15: Confidence with decision making processes (U)

Illustration: "It [the job] allows me to make decisions above what you'd be doing on the ward." (Taylor, 1999; p.68) 
Finding 16: Prioritising (U)

Illustration: "... as a quick overview I saw it as a pressing thing that needed to be done." (Taylor, 1999; p.69)

Finding 17: Willing to act to improve a situation (C)

Illustration: 'She therefore had no hesitation in rectifying a situation she felt 'so strongly about'. (Taylor, 1999; p.70)

Finding 18: Being assertive (U)

Illustration: "I made suggestions well and if I thought they were umm important, sort of reinforced them ... I was assertive." (Taylor, 1999; p.74)

Finding 19: Confidence in own ability enables nurse to question inappropriate medical staff decisions. (U)

Illustration: "And I just said it's [a postural blood pressure] totally inappropriate. It's just not warranted and if you're not competent enough to assess this patient I'll get someone else to do it." (Taylor, 1999; p.97)

Finding 20: Comfortable with level of expertise (U)

Illustration: "...you can make suggestions without being - oh them biting back and saying it's none of your business. Umm, I think too it's all to do with your own confidence and where you are within nursing and within yourself... I suppose in this role you have to do ... if you don't say anything nothing ever happens..." (Taylor, 1999; p.99)

Finding 21: Anticipation (U)

Illustration: "...you start thinking on your feet. You start thinking ahead of what things can go wrong and then trying to fix them before they actually occur, or intervening before they occur." (Taylor, 1999; p.112)

Finding 22: Confident to work beyond role (U) 
Illustration: "I felt confident in a way, I mean I knew we were doing stuff that, we weren't really [slight pause] qualified or whatever - for want of a better word, to do but I knew sort of, I had the knowledge and skills so hopefully we could fix it in the end..." (Taylor, 1999; p.98)

Finding 23: Intervene in chain of care if necessary (U)

Illustration: "If we find something that we think is acutely a problem and they shouldn't go home, they should be seen sooner; we would actually intervene in the chain of care and organize for that patient to see another doctor"(Walters, 1996; p.6)

\section{Category 9 summary - Intuitive knowledge: APNs demonstrate intuitive knowledge in their practice.}

Finding 1: Performing their role instinctively $(\mathrm{C})$

Illustration: '...the everyday experience of being a nurse consultant is lived through rather than spoken about or reflected on.' (Walters, 1996; p.5)

\section{Finding 2: Instinct (C)}

Illustration: 'Just by observing the patient the CNS can sense if they are really sick and will watch for signs of deterioration.' (Borbasi, 1999; p.26)

Finding 3: Intuitive - knowledge taken for granted (U)

Illustration: "I didn't know why this patient was deteriorating, but he clearly was, and yet other people [doctors] would come along and say, "Mr so and so's okay, no change from yesterday'. But he wasn't okay, he was changing. The senior nurse on said: 'I think he's dying', and three days later he was dead." (Borbasi, 1999; p.21); 'more inclined to pick up when something is not normal without them [the patient] necessarily saying anything." (Borbasi, 1999; p.23); "We felt she needed 
help there and then and quickly". (Borbasi, 1999; p.25); "I can be looking after a patient who is not well and I can often see they are going to be very unwell in a short period of time..." (Borbasi, 1999; p.25)

Finding 4: Intuitive awareness that further investigations were required (U)

Illustration: "I suspected that it could be angina type symptoms. She wasn't complaining of any other sort of symptoms and I thought it was necessary to get this investigated before she was due to come in and have her operation." (Taylor, 1999; p.66)

Finding 5: Instinctive feeling (U)

Illustration: "I got the feeling she wasn't telling me everything" (Taylor, 1999; p.81)

Finding 6: Insight (U)

Illustration: "I just felt that, that was important to get them [plastic surgeons] involved." (Taylor, 1999; p.82)

\section{Category 11 summary - Responsibility and accountability: APN"s have a strong sense of responsibility and accountability.}

Finding 1: Accountability and responsibility (U)

Illustration: "What happens if we've made a decision and we've done a written report and the patient goes to theatre as a result of that report and they open them up where we've indicated and nothing is found?" (Walters, 1996; p.6)

Finding 2: Ability to justify decisions to others (U)

Illustration: "we have to stand up at the meetings in front of the medicos and actually justify what we've done" (Walters, 1996; p.7) 
Finding 3: Delegation skills in time of crises to ensure needs of all patients are met (U)

Illustration: "I was thinking at two hundred miles an hour. I was already thinking of what was going on with the patient. I was thinking about the fact that I'd left twelve patients at my end of the ward unattended, so I was prompting my junior staff to make sure they were okay and to start settling them." (Taylor, 1999; p.64)

Finding 4: Responsibility to patients (U)

Illustration: '...would decide 'about the order in which we operate on people'. She considered this a fairly responsible task.' (Taylor, 1999; p.67)

Finding 5: Responsibility and obligation within the role leads to a desire to act in certain situations $(\mathrm{C})$

Illustration: "...sense of obligation and responsibility as an educator to address the situation." (Taylor, 1999; p.70)

Finding 6: Feelings of responsibility, accountability, professional judgement (U) Illustration: "...there was a big problem with what was happening in nursing practice there that I needed to address, or that I felt I needed to address." (Taylor, 1999; p.70)

Finding 7: Responsibility for whole ward situation (U)

Illustration: '...that was another thing that I was thinking about, is making sure the patients were covered." (Taylor, 1999; p.73)

Finding 8: Multiple levels of supervision and responsibility (C)

Illustration: '...he supervised the other Registered Nurse (RN), and reviewed the ward situation from time to time, both this ward and the ward he was relieving on.' (Taylor, 1999; p.73) 
Finding 9: Strong sense of accountability to patient, profession and organisation (U)

Illustration: "I was annoyed. Umm, that here was a patient who was in someone's care and they weren't receiving the care that they were entitled to ... I suppose some of that annoyance was also anger as well. And it reflects not only ... the person that's missing out on the care, ... it reflects on nursing care that's being provided, really by the hospital." (Taylor, 1999; p.102).

\subsubsection{Metasynthesis 4}

Negative experiences: Advanced practice or expert nurses working in Australian acute care settings are confronted with many negative experiences resulting from organisational barriers as well as frustrating interactions with medical and nursing staff. Being required to complete a large component of administrative duties detracts from time for patient care and contributes to work overload. Organisational pressures and resource imbalances can cause the nurses to work beyond his/her role and make them feel responsible for filling gaps within the system. The negative experiences can affect the nurses at a personal and/or professional level. A lack of understanding of their role by other staff may cause the nurses to feel professionally isolated.

This metasynthesis was compiled from 3 categories and 41 findings. Illustrations from the data to support each finding are included below. Levels of credibility are also included for each finding. 
Category 4 summary - Administrative work: having to do a large component of administrative work detracts APNs from patient care and contributes to overtime, work overload and frustration.

Finding 1: Administrative duties add to APN workload (C)

Illustration: 'Nurse consultants who are expected to manage clinical services can experience role overload because of the lack of appropriate administrative support.' (Walters, 1996; p.5)

Finding 2: Solely responsible for substantial amount of administrative duties (C)

Illustration: 'Administration activities formed a substantial part of the palliative care nurse consultant's role. Participants mentioned their management activity in direct contrast to their clinical role and while recognising the value of keeping records, they often worked alone, responsible for managing their own paperwork and filing.' (O’Connor, 2008; p.155)

Finding 3: Impact of burden of administration work (C)

Illustration: 'These administrative duties imposed on clinical and educational time and placed extra burden on already restricted working time.' (O'Connor, 2008; p. 155)

Finding 4: Uncontrollable workload factors (C)

Illustration: 'Being able to maintain a focus on nursing practice creates unique challenges for nurse consultants' (Walters, 1996; p.6); 'Being expected to cope with other health professionals' unfinished work can divert the energies of the nurse consultant from clinical nursing practice issues to administrative and secretarial functions.' (Walters, 1996; p.6) 
Category 7 summary - Organisational factors: organisational factors can affect APN experience and service utilisation

Finding 1: Blocked by organisational red tape (C)

Illustration: 'Some participants spoke of knowing intuitively the needs of the individual yet they were hampered by protocols that did not permit them access.'(O’Connor, 2008; p.155)

Finding 2: Service delay due to organisational processes (C)

Illustration: 'This obstruction meant they had to wait until a crisis occurred before they would be contacted to give advice or refer to other health professionals.' (O’Connor, 2008; p.155)

Finding 3: Work beyond role (C)

Illustration: '...capable of expanding her role to 'bridge the gaps' in the system'(Borbasi, 1999; p.25)

Finding 4: Taken for granted $(\mathrm{C})$

Illustration: 'The taken-for-grantedness of nurses and nursing practice is reflected in the somewhat unreasonable expectations and workloads...' (Walters, 1996; p.6)

Finding 5: Imbalance of resources and workload (C)

Illustration: '...in many instances, nurse consultants experience unreasonable pressures because they attempt cope with inadequate resources and an excessive case load.' (Walters, 1996; p. 7)

Finding 6: Lack of support with discharge planning processes (U)

Illustration: "...complex discharge planning is poorly known" (O’Connor, 2008; p.154)

Finding 7: Organisational restraints causing internal conflict (U) 
Illustration: "I sort of have the twinge of, like I should have said no, or made the ortho reg come up and see this lady or do something but, I sort of know that that really wasn't a possibility; or not for at least a couple of hours if not longer." (Taylor, 1999; p.73)

Finding 8: Empathy for and frustration with organisational processes (C)

Illustration: '....was annoyed that standards of care had to suffer because of an organisational hitch, however he understood the pressures placed on the institution.' (Taylor, 1999; p.74)

Finding 9: Institutional influence on advanced practice (C)

Illustration: "II don't think advanced practice is just clinical skills". She believed it's about how an institution works, policy development, conflict resolution and delegation, which was the focus of her story.' (Taylor, 1999; p.80)

Finding 10: Organisational influence on practice (U)

Illustration: "I think it's [advanced practice] is also about, ahh, being aware of how an institution functions, how a hierarchy functions. The way things are supposed to go correctly, and the channels to follow if they don't." (Taylor, 1999; p.110)

Category 8 Summary - Negative experiences: Negative experiences with staff relationships, organisation and workload can impact greatly on the APN experience at a personal and professional level.

Finding 1: Role development difficult (C)

Illustration: '...there were some challenges that stifled its development and rendered it difficult to professionally classify or fit neatly into the scope or practice of nurses.' (O’Connor, 2008; p.155) 
Finding 2: Emotionally traumatic (U)

Illustration: "...sometimes it get hard, really hard if you are close to patients or it's too traumatic with situations happening all at once. Then it's hard to keep the energy going." (O’Connor, 2008; p.156)

Finding 3: Overwhelming (U)

Illustration: "...getting too overwhelmed with the busy-ness and the emotional side of it". (O’Connor, 2008; p.156)

Finding 4: Working beyond expected hours (C)

Illustration: 'Some participants spoke about truncated lunch times, working overtime to collate records and filing and coming in early or finishing late in order to keep pace.' (O’Connor, 2008; p.155)

Findings 5: Resentment (U)

Illustration: "[And] I think you end up resenting the extra time that you do." (O’Connor, 2008; p.156)

Finding 6: Draining (U)

Illustration: "I think that if you're constantly working overtime all the time that gets very draining as well."(O’Connor, 2008; p.156)

Finding 7: Misunderstanding of role (C)

Illustration: 'The palliative care nurse consultant's role transcended boundaries and in fulfilling a gamut of needs, their functions were not well understood or promoted.' (O’Connor, 2008; p.155)

Findings 8: Time poor $(\mathrm{C})$

Illustration: 'Time was an issue for others, as they felt impoverished of sufficient time to do what was required of them.' (O'Connor, 2008; p. 155)

Finding 9: Burdensome (C) 
Illustration: 'The needs of people could be overpowering and the palliative care nurse consultants could feel overwhelmed with the burden of tasks at hand.' (O’Connor, 2008; p.155)

Finding 10: Awareness of and concern over different skill mix and levels of expertise $(\mathrm{C})$

Illustration: 'She highlighted issues of concern in relation to a deficit in some staff's knowledge of nursing spinal injury patients and associated bowel care, and the poor skill mix that was occasionally evident on weekends in this ward.' (Taylor, 1999; p.63)

Finding 11: Busy $(\mathrm{C})$

Illustration: 'A palliative care nurse consultant may have seen as many as 20 people (with or without their families) a day within the hospital.' (O'Connor, 2008; p.154)

Finding 12: Coping mechanisms (C)

Illustration: '...the ability to be flexible and not to be overwhelmed by the diversity and relationships they had to negotiate.' (O’Connor, 2008; p.153)

Finding 13: Pressure from organisation (U)

Illustration: "... a lot of pressure with discharge to get people out..." (O’Connor, 2008; p.154)

Finding 14: Expected to make decisions to fill the gaps (U)

Illustration: "...it's almost an unwritten thing for CNS as part of their role to make those sorts of interim decisions because doctors aren't always here...it takes time for them to get here and what do you do with this patient in the meantime?"(Borbasi, 1999; p.27)

Finding 15: Recognising potential overload due to staff skill mix (U) 
Illustration: "No matter how competent the EN [Enrolled Nurse], s/he does not have the knowledge or experience and therefore is not an equal partner - and while on an ordinary night this is of no consequence, on another night it is a load for any one sister to carry ..." (Borbasi, 1999; p.26)

Finding 16: Level of expertise assists coping ability but doesn't help in meeting demands (U)

Illustration: "I have the expertise to cope...I just don't have enough hands to be in more than one place at a time." (Borbasi, 1999; p.26)

Finding 17: Frustration at medical staff (U)

Illustration: "They just sit down and ask questions and then it's only what the patient chooses to tell them" (Borbasi, 1999; p.23); "Because I know damn well the doctors haven't" (Borbasi, 1999; p.25); "She [intern] didn't really do very much. (Borbasi, 1999; p.26)

Finding 18: Constrained by limited management responsibilities (C)

Illustration: 'Nurse consultants who do not have any line-management responsibilities can experience frustration by not being able to directly influence and change nursing policy and practice.' (Walters, 1996; p.5)

Finding 19: Concern over being utilised appropriately (U)

Illustration: "I think sometimes there is - it is a double edged sword. In some ways I think they (other nurses not specialised in palliative care) are just happy to hand the care over and not have to do it." (O’Connor, 2008; p. 153)

Finding 20: Isolation from nursing profession (C)

Illustration: 'Being the only nurse consultant in a specialized health care team can lead to professional isolation.' (Walters, 1996; p.7)

Finding 21: Having to finish others work (U) 
Illustration: "everybody else's leftover work gets piled on to my desk" (Walters, 1996; p.6)

Finding 22: Conflict with medical decisions due to own level of expert nursing

Illustration: "But within a five second decision I'd have decided that he was incompetent because he wasn't worried about her venous access, he wanted a postural B/P [blood pressure]. And that wasn't my primary ... That wasn't the train of thought that I had ... But I saw her, I knew that she had stopped breathing, I knew that she had no carotid [pulse], because I was the one feeling for it and I couldn't find it..." (Taylor, 1999; p.62)

Finding 23: Conflict within decision making process (U)

Illustration: "So it was a bit of a tricky decision as to sort of just leave her and, she would end up compounding or being in a lot of pain, being quite sore, or trying to do something" (Taylor, 1999; p.73)

Finding 24: Frustration at lack of adequate admission assessment (U)

Illustration: "...often [it] is very complicated because the paperwork doesn't come with the patient; because they haven't really been admitted; they haven't gone through admissions and more importantly they haven't been seen by medical staff and stabilised in casualty. And so they are sent up, often in quite a lot of pain, often all their injuries aren't fully assessed and there may be another injury that we are not aware of at the time when they arrive on the ward." (Taylor, 1999; p.78)

Finding 25: Negative resolution (U)

Illustration: "...and as much as I had tried to use all my conflict resolution skills, nothing was resolved." (Taylor, 1999; p.79) 
Finding 26: Frustration as patient being affected (U)

Illustration: "...the frustrating thing for me in all of this is the patient was being disadvantaged' (Taylor, 1999; p.79)

Finding 27: Conflicting loyalties (U)

Illustration: "You're in a really precarious position, because yes you can be a patient advocate to a point, which I really believe should be. But at the same time I am an employee of the hospital and you can't umm, you can't [pause] ... put the hospital down..." (Taylor, 1999; p.80).

\subsubsection{Metasynthesis 5}

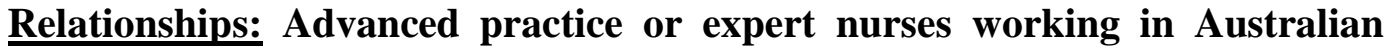
acute care settings are required to build and maintain positive, multidisciplinary relationships which may extend beyond their department and even their organisation. They utilise expert communication skills and professional behaviour to conduct and nurture these relationships as they are aware that the relationship may become symbiotic or antagonistic. Their professional demeanour is paramount within this experience.

This metasynthesis was compiled from 4 categories and 33 findings. Illustrations from the data to support each finding are included below. Levels of credibility are also included for each finding.

Category 10 summary - Relationships: multi-disciplinary relationship building and maintaining positive relationships is essential component of the APN experience. 
Finding 1: Supportive relationships with medical staff rewarding and necessary (U)

Illustration: "It gives you back-up, and then you also have guidance when you require it". (Walters, 1996; p.6)

Finding 2: Positive relationships affect practice (U)

Illustration: "...if you don't have a good relationship with the medical staff then you're not going to grow and learn and have your decisions tested to make sure you've actually gone along the right way". (Walters, 1996; p.6)

Finding 3: Coordinating multidisciplinary healthcare teams (U)

Illustration: "...yes, I am a clinical coordinator" p.6 "I decide which one of the clinicians is best to see them"(Walters, 1996; p.6)

Finding 4: Back up for junior medical staff (U)

Illustration: "It happens quite often because a lot of the times while they know that patient they might not know what's been going on immediately; and they are really asking you to double check themselves." (Borbasi, 1999; p.24)

Finding 5: Advisory role (C)

Illustration: '...she says that interns will approach her to ask her advice on the treatment they are about to prescribe.' (Borbasi, 1999; p.24)

Finding 6: Leading multidisciplinary team (U)

Illustration: "...very much my forte to lead the team in medical, allied health and nursing staff" (O’Connor, 2008; p.154)

Finding 7: Multidisciplinary team (U)

Illustration: "...a range of expertise within all those disciplines." (O'Connor, 2008; p.153)

Finding 8: Involvement in teams (U) 
Illustration: "We go to their [referring units] once weekly team meetings as well."(O’Connor, 2008; p.154)

Finding 9: Care extends beyond patient (C)

Illustration: 'Individual care was not seen as limited to ill people and their families, as many palliative care nurse consultants also discussed their care of nursing staff, medical colleagues and allied health professionals.' (O'Connor, 2008; p. 154)

Finding 10: effort involved in relationship building (U)

Illustration: " I do go to a lot of trouble to get on with everybody so that I have a good working relationship and not seen as someone who just barrels in and orders everybody around"(O’Connor; 2008; p.154)

Finding 11: Precarious working relationships (C)

Illustration: "One participant described how she "walked a tightrope" when contributing to staff knowledge.' (O’Connor, 2008; p.154)

Finding 12: Facilitating group discussion for patient care (U)

Illustration: "... a high proportion of families would have a sit down meeting that would involve usually the Registrar, O.T., Physio, Social Worker, ourselves, the primary care nurse, patient and family. So you might sit down with ten people in the room to actually do that." (O’Connor, 2008; p.155)

Finding 13: Skillful relationship building (U)

Illustration: "...they've asked me to be involved and I would start off, very gently about what their understanding of what was going on and get them to tell me rather than me tell them how things are going for them." (O'Connor, 2008; p.155) 
Finding 14: Mentoring relationship with medical staff if inadequate nursing support present $(\mathrm{C})$

Illustration: 'Without the appropriate professional nursing-support structures, nurse consultants can seek their professional mentorship from the medical staff.' (Walters, 2008; p.7)

Finding 15: Supportive relationships (U)

Illustration: "you're not isolated...there's always someone to bounce ideas off." (O’Connor, 2008; p.154)

Finding 16: Positive, interactive relationships with doctors (U)

Illustration: "... and I really, really find it rewarding to be able to interact with the doctors on such a one-to-one level which you don't necessarily get on the ward as well." (Taylor, 1999; p.68)

Finding 17: Colleague advocate (U)

Illustration: "I would probably say I was an advocate for the consultant and registrar and the registered nurse." (Taylor, 1999; p.76)

Category 15 summary - Communication skills: APNs demonstrate expert communications skills in their professional relationships as well as patient and staff interactions

Finding 1: Empathetic \& trusting communication (U)

Illustration: "When they see you as a nurse, not a technician, they tend to open up to you and tell you more." (Walters, 2008; p.8)

Finding 2: High level of telephone communication skills (C) 
Illustration: 'Having good telephone skills transcends the physical separation of the nurse and the patient in that the patient still feels they matter to the nurse.' (Walters, 1996; p.8)

Finding 3: Need for clarification (U)

Illustration: "If I'm getting the wrong information, the information is incorrect, we will restart and tease things out." (O’Connor, 2008; p.155)

Finding 4: Skills required for speaking with people in various emotional states (C)

Illustration: “...necessitating the palliative care nurse consultants to have expertise in communication and a range of skills in speaking with vulnerable and distressed people.” (O’Connor, 2008; p.154-155)

Finding 5: Aware of need to debrief junior staff (U)

Illustration: "I've got to think, (I got), to remember to speak to that enrolled [nurse] about what happened and to the student [nurse]." (Taylor, 1999; p.63)

Category 17 Summary - Consultancy role: consultancy and liaison can be extensive and may link the APNs unit to other internal departments and at times, areas external to the hospital environment.

Finding 1: Liaison role (U)

Illustration: "...as a lynch pin liaison between community-based palliative care and nursing services in the hospital". (O'Connor, 2008; p.153)

Finding 2: Conduit (U)

Illustration: "...flow of information..."(O’Connor, 2008; p.154)

Finding 3: Readily available resource for other departments 
Illustration: "We are also available to liaise with patients who have come into the Accident and Emergency Department. Sometimes we get referrals from the Intensive Care Units or the Coronary Care Units. So basically anywhere throughout the hospital or the outpatient clinics, we get called to see patients. "(O’Connor, 2008; p.154)

Finding 4: Internal and external consultant (C)

Illustration: 'The palliative care nurse consultants believed they function as consultants both in a hospital and outside.' (O'Connor, 2008; p.154);

Finding 5: Consultant (U)

Illustration: "To say can you look at them and give us your opinion." (O’Connor, 2008; p.153); "it's a consultative role." (O’Connor, 2008; p.154)

\section{Category 18 summary - Professional behaviour: acting in a professional manner in all circumstances is paramount to the APN experience.}

Finding 1: Composed (C)

Illustration: 'It was important to [the nurse] that she maintain composure despite feeling 'angry and furious' that this type of admission had occurred again.' (Taylor, 1999; p.78)

Finding 2: Professional growth (C)

Illustration: '...she seemed to take her professional growth very seriously.' (Taylor, 1999; p.83)

Finding 3: Working within legislative and organisational boundaries (U)

Illustration: "...abiding by (the) guidelines of hospital policies and procedures and all those other things and by the Acts and all that sort of stuff..." (Taylor, 2008; p.108) 
Finding 4: Leading by example (U)

Illustration: "...acting as a leader just directing and making sure that everything was going smoothly; keeping everyone calm and relaxed." (Taylor, 2008; p.109) Finding 5: Coordinating in a professional manner (U)

Illustration: "Probably acting as a leader just directing and making sure that everything was going smoothly, keeping everyone calm and relaxed. Being professional at all times." (Taylor, 1999; p.76)

Finding 6: Maintaining professional behaviour (U)

Illustration: "...being professional at all times." (Taylor, 1999; p.76)

\subsubsection{Metasynthesis 6}

Patient centred experience: Patient care is central to the advanced practice nurse experience in Australian acute care settings, and providing support to patients and their families is a priority. The nurses demonstrate a deep, personal level of interaction in their patient care relationship which is built on empathy and trust. They may instigate patient treatment based on their expert assessment skills. The nurses are able to discern expert nursing care from medical care and positive patient outcomes and interactions can contribute to job satisfaction and rewarding experiences. Colleague support is intertwined with and integral to the patient care experience.

This metasynthesis was compiled from 3 categories and 43 findings. Illustrations from the data to support each finding are included below. Levels of credibility are also included for each finding. 
Category 12 Summary - Supportive resource: APNs provide support to staff, patients, families and each other.

Finding 1: Long term support for families (U)

Illustration: "...talking to families that have had perhaps twenty/thirty year connections with some of the units" (O'Connor, 2008; p.154)

Finding 2: Support needs recognised by other staff (U)

Illustration: "The staff see a need for...support for families..." (O'Connor, 2008; p.153)

Finding 3: Colleague support (U)

Illustration: "I guess in many ways we are a backstop for the staff." (O’Connor, 2008; p.153) "...or even support for themselves" (O’Connor, 2008; p.153)

Finding 4: Family support (U)

Illustration: "I went down there and reassured them that she was okay ... I just reassured them that she was alright, and that she was responding." (Taylor, 1999; p.63)

Finding 5: Emotional support from colleagues (U)

Illustration: "...and if it gets too difficult you know that the other person on the team will go and do it for you." (O’Connor, 2008; p.154)

Finding 6: Care extends to family (U)

Illustration: "I'm sure that the family appreciated, like I had no hesitation in thinking that the family appreciated everything we did." (Taylor, 1999; p.65)

Finding 7: Supporting other nurses(C)

Illustration: '...commitment to supporting the nurse.' p.70

Finding 8: Informing family (U) 
Illustration: "...got the impression it was important to keep them [the family] fully informed." (Taylor, 1999; p.81)

Finding 9: Professional empathy (U)

Illustration: "... and I thought I'll let, I'll just let it go because it's a lesson learnt that sometimes you can't trust the medical staff. As much as they're medical staff they're novices in their own profession, they're only beginners." (Taylor, 1999; p.97)

Finding 10: Advocacy role extending beyond patient (U)

Illustration: "I would probably say I was an advocate for the patient, an advocate for the consultant and [orthopaedic] registrar and the registered nurse." (Taylor, 1999; p.102)

Finding 11: Empathy for junior staff through acknowledgement that experience comes from exposure to clinical situations and knowledge (U)

Illustration: "...possibly they don't have a lot of spinal knowledge, about maintaining alignment and that's not their fault but inexperience, and if you haven't been given the opportunity to experience nursing spinal injury patients, or nursing just patients post spinal surgery, which we don't get a lot of, you know they just haven't got that experience." (Taylor, 1999; p.92)

\section{Category 13 summary - Patient care: the patient is central to the APN experience}

Finding 1: Get to know patient at a deeper level than doctors (U)

Illustration: "...the doctors just don't have that time, or they don't make the time....you couldn't get them to make a bed so they don't have time to get to know what sort of social background the patients' comes from - what's going on with the 
patient's family before they left home or any of those things."(Borbasi, 1999; p.23)

Finding 2: Prepare patient for bad news (U)

Illustration: "When I'm taking down a graft I always ask them [the patient] if anybody has explained to them what the graft is going to look like. And then I say it's going to look dreadful and so on and so forth..."(Borbasi, 1999; p.25)

Finding 3: Empathy (U)

Illustration: "...and I always have a box of tissues ready." (Borbasi, 1999; p.25)

Finding 4: Initiating patient treatment (U)

Illustration: "[you instigate] the simple procedures that will tide [the patient] over until someone gets there to help" (Borbasi, 1999; p.27)

Finding 5: Clinical assessment (U)

Illustration: "I am called on to see patients and assess them and maybe it might be something as simple as...symptom management"(O’Connor, 2008; p.153)

Finding 6: Personal trust (C)

Illustration: 'Information was confided....about their fears, their families, their perceptions about life and death. Family members also disclosed their innermost apprehensions about treatments, prognoses and emotional impact...' (O'Connor, 2008; p.15)5

Finding 7: Confidante (C)

Illustration: 'In the midst of pain and suffering the nurses were the "keepers of the stories"' (O’Connor, 2008; p.155)

Finding 8: Patient at centre of care

Illustration: "[dealing with] what is the patient's understanding; trying to work out where they want to be; whether they are comfortable at the moment; who we 
can speak to (about them); what's their anticipation of what future care would be."(O’Connor, 2008; p.155)

Finding 9: Recognition of patient perspective (U)

Illustration: "...talking to families that have had perhaps twenty/thirty year connections with some of the units." (O’Connor, 2008; p.154)

Finding 10: Interacting with patient before medical staff (U)

Illustration: "I've done an interview with the patient on the phone, and then the first person who usually sees them is a medical practitioner." (Walters, 1996; p.6)

Finding 11: Enabling patient to talk about their condition (U)

Illustration: "I get the person to talk about what's happened to them....how does it feel, what are the limitations on their lives...I give them a chance to ventilate." p.8"My experience with working with very ill patients...my experience of nursing...enables me to help them verbalize all their problems and to help them cope with the situation." (Walters, 1996; p. 8)

Finding 12: Recognising and acknowledging patient's experience of their condition (U)

Illustration: "...the patients are angry that they may be going to lose a part of their body."(Walters, 1996; p.8)

Finding 13: Differing aspects of patient care (U)

Illustration: "It could be that the patient is totally managed by the doctor, but I may see them for some counselling. I may also see them for advice on specific treatment modalities, looking at the correct use of medication and how to get them functioning better." (Walters, 1996; p.6)

Finding 14: Ability to do thorough patient assessment to identify current \& anticipated patient needs (U) 
Illustration: "...I was pretty confident that we did a thorough assessment of her [the patient] and identified relevant issues with regards to her discharge planning and also her medical needs." (Taylor, 1999; p.68)

Finding 15: Patient is first priority (U)

Illustration: "I felt confident and comfortable to, to take those steps because ultimately the patient is paramount." (Taylor, 1999; p.70)

Finding 16: Patient focus $(\mathrm{C})$

Illustration: '...strong sense of patient focus.' (Taylor, 1999; p.70)

Finding 17: Patient advocate (U)

Illustration: "...'cos I also suggested to them, you know if you're going to get plastics involved and they want to do some grafting or anything, if they were considering doing the nail, then they did it all at the same time with one anaesthetic." (Taylor, 1999; p.82)

Finding 18: Alleviating patient anxiety (U)

Illustration: "...but I think he seemed happy that we actually were providing him with some information and I just left him with 'if you've got any questions, or you want to know what's going on, just ask, you know we're not going to bite your head off. I'm not going to profess I know all the answers". I said "we can certainly try and find the answers". He seemed to be happy with that." (Taylor, 1999; p.82)

Finding 19: Patient advocacy (U)

Illustration: "I felt very strongly about it at this point in time because I just felt all I was trying to do was be an advocate for the patient and try umm, look out for his best interests." (Taylor, 1999; p.83)

Finding 20: Sense of promoting continuity of care (U) 
Illustration: "I felt I was doing the right thing for the patient, for continuity of care." (Taylor, 2008; p.104)

Finding 21: Making patient feel at ease (U)

Illustration: "You have just got to be very careful in front of the patient as to make sure they are completely at ease. That you really know what you are doing." (Taylor, 1999; p.103)

Category 16 Summary - Positive experiences: APNs have positive and rewarding experiences which are usually related to positive patient care experiences.

Finding 1: Satisfaction (U)

Illustration: "...making a difference." (Walters, 1996; p.7)

Finding 2: Rewarding (U)

Illustration: "It can be very inspiring. It can make me feel good if I can go in and help a family at such an intense time, be more okay about the crisis." (O'Connor, 2008; p.155)

Finding 3: Innovative (U)

Illustration: "...breaking new ground."(O’Connor, 2008; p.153)

Finding 4: Feeling competent and satisfied (U)

Illustration: "I, umm, felt competent and I felt that we'd done a good job" (Taylor, 1999; p.64)

Finding 5: Content (U)

Illustration: ‘...that's good nursing." (Taylor, 1999; p.65)

Finding 6: Reward from positive patient outcome (U) 
Illustration: "...and the patient thanked us and kissed our hand as well and was so grateful and that was a rewarding feeling like, a positive feeling and it made you think that's what I'm here for, that feeling." (Taylor, 1999; p.65)

Finding 7: Positive outcome for patient and nurse (U)

Illustration: "So I sort of feel, yeah I feel good about it because it ended up in a positive way, we helped the lady, and we sort of worked as a team and everything went okay. The outcome was positive". (Taylor, 1999; p.73)

Finding 8: Empowerment (C)

Illustration: 'she felt 'empowered' by making suggestions and having them taken seriously.' (Taylor, 1999; p.82)

Finding 9: Positive feeling (C)

Illustration: 'But she felt 'good' that her suggestions were taken up and she was able to 'initiate' holistic care for this patient.' (Taylor, 1999; p.83)

Finding 10: Doing a good job (U)

Illustration: "I felt good about - like what had happened - in that things had been picked up for the patient." (Taylor, 1999; p.102)

Finding 11: Sense of completion (U)

Illustration: "They found it was a lot more beneficial to have the pre-admission education the first time round ... It makes you feel good, and it makes you feel that there must be something good in the system at the moment." (Taylor, 1999; p.105) 


\section{Chapter 5 - Discussion}

\subsection{Introduction}

This study was undertaken to perform a systematic review of the qualitative evidence on the experience of being an advanced practice nurse working in Australian acute care settings. The four papers included in the metasynthesis provided 216 findings which were collapsed into 6 synthesised findings under the headings of expert knowledge; spectrum of work activities; confidence and familiarity; negative experiences; relationships and patient centred experience. These findings have uncovered a greater understanding of the complexity of the role of APN in the chosen context, and consequently provided a deeper insight into the essence of an APN in the defined context.

In her book on meta-study of qualitative health research, Paterson et al., (2001) suggests,

"The appeal of a meta-synthesis lies in our hunger for more true, more accurate, or more real explanation[s] of phenomena...” (p.110)

The purpose of this meta-synthesis was aligned with this quote in that it aimed to identify a 'more real' explanation of an APN. The context-specific nature of the review provides a pragmatic aspect to the findings as it will enable the Australian nursing profession to implicitly relate to these results.

The search process confirmed that many different titles have been used and are still in use to describe Australian advanced practice roles, including nurse practitioner, clinical nurse consultant, nurse specialist and expert nurse. Due to 
this variety in titles, a broad search strategy was undertaken and hand searching was required of many reference lists to identify appropriate papers for inclusion. Although only nine papers were suitable for critical appraisal, out of the 154 papers that had abstracts retrieved, only 29 had the words 'advanced practice' in their title. Of these, 13 were government publications, and only 14 pertained specifically to advanced nurses in Australian contexts; the remaining two studies included overseas settings. Consequently, the search process highlighted that the term advance practice nurse is not widely used within nursing research in Australia at this time, especially in relation to acute care settings. It is difficult to know if this is due to lack of understanding of how the term specifically applies to nursing roles or if it just not being used much in acute care settings for other reasons. More frequently, it was found that many papers set in acute care settings identified the nurse with a role title that included the area of practice as well as a nursing role, for example, mental health nurse practitioner (Elsom, Happell, \& Manias, 2005) or intensive care unit liaison nurse (Chaboyer, Foster, Foster, \& Kendall, 2004). No papers on Nurse Practitioners were found to meet inclusion criteria for this review.

The chosen papers for inclusion identified variation in titles also, with the title of clinical nurse consultant most frequent, however clinical nurse specialist was also identified in one paper (Borbasi, 1999) and the dissertation on advanced practice orthopaedic nurses (Taylor, 1999) did state that the nurses were experts in their field of practice, without specifying role titles. These studies were included because at the time of each study the nurses were reported as working at an advanced practice level. As discussed by Gardner et al, (2007), viewing different 
titles under the banner of advanced practice can be confusing and since definition and regulation of the Nurse Practitioner role has been achieved, ongoing work in achieving consistency in titles and qualifications for acute care expert or advanced nurses must progress.

Analysing studies with different titles of advanced practice nurses may be seen as a limitation or criticism of this review. By attempting to compare different titles of nurses, there may be variation in years of clinical experience and there is the potential to include a 'new' role title, in which the participants may have been employed for only a short amount of time. As with many phenomenological studies, demographic data is not often collected, therefore it may not be possible to analyse the years of experience for each of the participants in the review. It should be clarified that the nurse is employed by the organisation in that particular role and it is beyond the scope of the review to be able to ascertain if the 'advanced role' meets any predetermined criteria; unless reported otherwise, there is the belief that the nurse has met the criteria set by the employer to fulfill an advanced practice role.

\subsection{Main findings}

The review identifies the experience of being an APN is multi-faceted and complex with intertwining issues that are influenced predominantly by the organisation within which they work, but also by the inherently unpredictable nature of working with people. Although the review discusses some of the various activities and role functions of the advanced practice nurse, it uncovers the complex and personal side of the role as experienced in this specific context. 
The first synthesised finding identifies that the nurses are utilising an expert level of knowledge in their practice. This finding suggests that the terms advanced practice and expert nurse may be interchangeable for this context. Each nurse is an expert within their practice environment and some are expanding their expertise to other areas within their organisation. The nurses interviewed believe that their specialty knowledge has a direct impact on their patient experience in some situations. This has been quantified in an American systematic review, whereby the use of clinical nurse specialists was found to reduce patient length of stay and consequent hospital costs (Newhouse et al., 2011), however as mentioned in the first chapter of this study, comparing Australian nursing practice to other countries may not be appropriate therefore similar Australian studies would be beneficial in order to support the qualitative evidence provided by the nurses in this study and provide a tangible aspect to what the nurses seem to already know about their practice.

The extent to which APNs experience and conduct educational activities, supervision responsibilities and mentorship roles is a significant finding in this review as it impacts positively and negatively on the nurse. Time spent by CNCs in informal education activities was previously studied by Jannings \& Armitage (2001) and was found to be poorly documented. However, the study was conducted on community CNCs, and it would be interesting to investigate actual time spent by acute care APNs on these activities. For each of the papers in this review, educational activities were highlighted as integral and impacting components of the role and they extended beyond the patient, to families, peers and medical staff. The educational component of their experience transcended 
role title; the nurse specialists were involved in education and supervision responsibilities as well as the clinical nurse consultants.

The second synthesised finding relates to the spectrum of work activities that APNs experience and identifies a range from routine, repetitive tasks, which may be specific to their context of practice (e.g. wound care, patient observations), to unpredictable, chaotic events where the APN must use their decision making skills and leadership abilities. The nurses report that they are sometimes overwhelmed by the diversity that their role entails, but others report that the confidence and familiarity they experience in the role allows the unpredictability to become an exciting and energizing aspect of their work. Consequently, it can be seen that aspects of this finding are intertwined with the third and fourth synthesised findings.

The paradoxical nature of the APN experience is discussed by Walters (1996) and also emerged in the three other studies, although in varying forms. Although the nurses exhibit and are acknowledged as utilising a high level of knowledge and skills in their patient care, they are also expected to undertake non-nursing duties such as administration work which removes them from patient care and leads to working above expected hours, potentially contributing to exhaustion and burnout. Walters describes this as a 'paradox of power' (Walters, 1996, p. 3), as also reported by Bull \& Hart (1995), and the paradoxical nature of APN practice has been supported in this review within many of the synthesised findings, particularly in relation to work activities, expert knowledge and relationships. It 
is interesting to note that although some may view the Walters' paper as outdated, the issues highlighted in the paper are still relevant.

The intuitive and insightful nature of the APN experience, as highlighted by the third synthesised finding, is possibly the most intangible and poorly articulated aspect of their practice. Intuition as part of expert practice is not a new concept, with literature and evidence of intuition being used as an essential part of clinical judgement and nurses' decision making (Benner \& Tanner, 1987; McCutcheon \& Pincombe, 2001; Rew \& Barrow, 2007). Intuition is described by McCutcheon and Pincombe (2001) as a synergy between knowledge, experience, and expertise; this review has identified that the APN experience may be a similar synergy and that the nurses themselves do acknowledge their intuitive knowledge. The use of the word "feeling" was found in many of the findings within the category of confidence and familiarity, which suggests the nurses themselves do sense a need for action but are often unable to articulate the exact need.

Although positive experiences are reported by the nurses, particularly in relation to positive patient outcomes and the intense personal aspect to relationships built by the nurses, the largest amount of findings is included in the fourth metasynthesis of negative experiences. Organisational pressures, lack of resources and lack of professional support are highlighted as factors affecting the nurses' experience. Professional isolation due to lack of understanding of the nurses' role is a major concern for the nursing profession. Defining and clarifying new positions prior to implementing them may assist in engendering support throughout an organisation. Organisational 'red tape' is seen as a frustrating 
component of the APN experience and the nurses reported that service delays often resulted, leading to a negative impact on patients, which increases their frustration. Being an employee of any organisation requires the employee to adhere to policies and principles determined by the organisation however the professionalism reported by the nurses in this review suggests that they do feel a responsibility and loyalty toward their employer. Therefore, the negative aspect of this situation may be addressed by supporting and encouraging APNs to be more involved with policy making within their organisation, particularly where policies directly affect their area of practice. Also, as mentioned above, greater administrative support would assist in decreasing some of the negative experiences for the APN.

The fifth synthesised finding of relationships identifies that positive and negative relationships are an integral part of the APN experience. This finding is also identified in the Lloyd Jones (2005) international systematic review. The clinical consultant role and clinical nurse specialist roles require a great deal of relationship building as consultation and liaison may extend beyond the units in which they work. Relationships are built, not only face-to-face, but across the telephone also, requiring the nurse to have a very high level of verbal communication skills. Findings pertaining to relationships with medical staff identified that a positive relationship with doctors allowed the nurses to build on their own knowledge and skills and increased their confidence in practice. Frustrations with relationships seemed to occur when communication was restricted or if supervision, education and/or mentorship boundaries were surpassed, creating extra workload for the nurse. Personal coping strategies to 
overcome some of these challenges involved, '...the ability to be flexible and not to be overwhelmed by the diversity and relationships they had to negotiate.' (O'Connor \& Chapman, 2008, p. 153). The category of professional behaviour is included in this synthesised finding as it is clear that the nurses value a level of composure and diplomacy amidst all their relationships; however it seems from the findings that the nurses' personal attributes also contribute to how they conduct their professional relationships.

This review highlights that a large component of the APN experience is based on patient centred care. Having the knowledge and skills to provide expert nursing care is identified but the review also uncovers attributes such as trust, empathy and being a confidante, as being an essential part of the nurse-patient experience. The findings support that positive patient experiences provide the nurse with greater job satisfaction and rewarding feelings but it also demonstrates the need for greater support for APNs who themselves are a frequent support for their patients, families and other staff. There is a high risk of burnout with such responsibility and mechanisms must be in place within acute care settings and the nursing profession to identify the risk and provide early intervention where necessary.

As discussed by Arbon (2004), clinical expertise and experience are very different concepts and being experienced as a nurse includes being able to characterise meanings and understandings that have developed over time. Being experienced as a nurse transcends technical expertise and implies that the nurse has an understanding of "their own and others' lived worlds" (Arbon, 2004, p. 155). 
This review has provided evidence from the nurses' voice which supports this concept and proposes that individual characteristics, organisational components and role factors intertwine and connect to create the complex experience of being an advanced practice nurse in Australian acute care settings.

\section{3 limitations of the Review}

As this review is part of a master's qualification, only one person (student) was required, as per course guidelines, to conduct the searches and select articles for further appraisal. This is a limitation of this review as two people involved in the selection process may allow for greater objectivity. However to compensate for this and to improve the dependability and credibility of the review, a third reviewer was used in the appraisal stage if there was any disagreement about appraisal scores between the first and second reviewer.

It is important to note that the scope of the review will be limited to the goal of answering the research question specifically and it is not designed to be a report on the overall state of advanced practice in Australian acute care settings. The papers chosen for the review were analysed according to the set inclusion and exclusion criteria so although there has been much research conducted on various other aspects of advanced practice nursing in specific fields within Australia, any papers excluded from the review must not be seen to be of low quality, rather that they did not specifically meet the inclusion criteria but may be suitable for inclusion in other systematic reviews with different inclusion criteria. 
The temporal parameters of this study $(1990-2011)$ may be seen as a limitation to the review as it has allowed incorporation of research on clinical nurse specialists, along with clinical nurse consultants. The discourse on specialisation and advanced practice should be considered here. In two of the four included studies the participants were specialists in their field of practice but reported to have advanced practice skills. In two of the other studies the participants were clinical nurse consultants, one population being specialised in palliative care.

Since 1990, the nursing profession has debated the inclusion of clinical nurse specialists as advanced practice nurses because the element of specialisation does not necessarily equate to advanced practice (Pearson \& Peels, 2002), and more recent literature suggests that clinical nurse specialists are not practicing at the level of advance practice nurses. It was a deliberate action to allow papers from 1990 into the review, in order to provide a historical timeline to the review. The arguments for differentiation of specialist practice from advanced practice are many, however as seen in this review many findings extracted from the earlier papers were similar to the findings within the other two papers, which may suggest that within the acute care setting, context of practice may affect the nurses' experience irrespective of their title. It does imply that further research is required to determine a national consensus both in practice and at an academic level of the differentiation or similarities between specialisation and advanced practice. 
Publication bias should always be a consideration for systematic reviews. Although one unpublished thesis has been included in the review there may be more unpublished studies that may not have been found in the search process.

\subsection{Implications for Practice}

There is a pragmatic aspect to this review as the implications for practice highlighted are specific to the functioning of the APN in the Australian acute care environment, however as discussed above, the results identify intertwining factors which, when combined, inform the overall experience of an APN in an Australian acute care setting.

A deeper understanding of the essence of being an APN may be of benefit for recruitment and retention planning. This review has identified that personal attributes such as trust, empathy, courage and stamina are required for the APN role, along with the ability to carry out the more defined tasks and activities within the role which have been discussed in other research studies.

Unfortunately the category with the highest amount of findings related to negative experiences, which included organisational factors. Health care organisations must be aware of the impact they have on the nurses' experience if they are to commit to retention of nurse's and to patient safety. Providing greater administrative support to APNs would be of benefit.

It is vital for APNs to be able to articulate their practice if it is to be enhanced and further analysed. Nurses should be encouraged to publish their work, especially 
from higher degree academic courses, as these in-depth studies may be able to contribute significantly to future practice. Nursing publications need to be valued and supported in order to quantify some of the currently intangible aspects of practice and reinforcing the importance of reflection and documentation of their reflections should be an essential part of the APNs work. Being provided time to do so is also necessary and may be a challenge; however the benefits in doing this would be immense as it would allow administrators to identify areas that require attention and it would assist the nursing profession to define and delineate nursing responsibilities and roles. It would also allow these valuable nurses to have a louder voice within professional and political circles.

The heterogeneity of the role titles within the included papers was notable and may further support the argument for nationally consistent titles, role definitions and role boundaries which already been called for in the literature on advanced practice within Australia (Duffield et al., 2011; Gardner et al., 2007). Despite the presence of the Royal College of Nursing Australia definition from 2006 (Royal College of Nursing Australia, 2006), and although this consistency would greatly assist practice, perhaps the call for a clearer definition is more specifically a call for definition of advanced practice roles in certain contexts, for example acute care advanced practice nurse or primary care advanced practice nurse. This may assist organisations in deciding which nursing roles are required for their service delivery. Formal consistent educational qualifications for APNs in acute settings may assist in providing this consistent and defined approach to advanced practice. Some states within Australia already have advanced practice post graduate courses available, however a national approach to this should be considered. 


\subsection{Implications for Future Research}

If the topic of advanced practice is to remain current in the Australian nursing then ongoing research must be conducted to identify if the title is being used more frequently within the nursing profession. Due to the limited number of papers found using the term advanced practice, it may be more appropriate, if conducting further reviews on this phenomenon, to use a specific title such as acute care nurse practitioner or clinical nurse consultant. Consistent titles, education and qualification criteria for an advanced practice nurse would allow greater uniformity for comparing roles in the future. Further systematic reviews on specific contexts of practice would also provide evidence for the nursing profession.

The context-specific nature of this review provides discussion on a specific aspect of Australian healthcare and therefore the findings may not be transferable to other country contexts, however the framework for the review could be utilised to conduct similar metasynthesis in other contexts. Further phenomenological research into other specific nursing roles in specific contexts would be of value to enable further understanding.

The findings of this review support and confirm that some of the findings found in the Lloyd Jones (2005) international systematic review are present in Australian acute care settings also. The review identified that relationships, role ambiguity and organisational factors are among the barriers to development and effective practice (Lloyd Jones, 2005) . However, according to Sheer \& Wong (2008), global development of the role is also impacted by the nursing profession within 
each individual country due to variations in nursing education and population characteristics (Sheer \& Wong, 2008). Contextual factors must be considered in further research to enable individual countries to have their own voice heard within the APN discourse.

\subsection{Conclusion}

The meta-synthesised findings from this review enhance our current understanding of what it means to be an APN supported by the voices of the nurses themselves. The review has identified that being an APN is a multi-faceted and complex experience, with intertwining issues that are influenced predominantly by the organisation within which the nurse works and also by the inherent unpredictable nature of working with people. Although the review discusses some of the various activities and role functions of the advanced practice nurse, it delves deeper to uncover the complex and personal side of the role as experienced in this specific context. Professional and organisational support is required to support these nurses otherwise they appear to be at great risk of burnout due to overwhelming demands and increased pressure to fill gaps in an increasingly burdened health care system. 
Appendices 
- Appendix I: Validation Tool for Inclusion Criteria

Verification form - Systematic Review

\section{Paper Title:}

Author:

Date:

\section{Inclusion Criteria}

\begin{tabular}{|c|c|c|c|c|}
\hline Criteria & yes & no & unclear & comments \\
\hline $\begin{array}{l}\text { 1. Does the paper acknowledge } \\
\text { nurses role as being an advanced } \\
\text { practice nurse (APN)? } \\
\text { Note - 'expert ', 'clinical nurse } \\
\text { consultant', 'clinical nurse } \\
\text { specialist and 'nurse practitioner' } \\
\text { are acceptable as advanced } \\
\text { practitioner }\end{array}$ & & & & \\
\hline $\begin{array}{l}\text { 2. Does the paper discuss the } \\
\text { experiences of being an } \\
\text { advanced/expert practice nurse? }\end{array}$ & & & & \\
\hline $\begin{array}{l}\text { 3. Does the nurse practice within an } \\
\text { acute or metropolitan hospital } \\
\text { setting? }\end{array}$ & & & & \\
\hline 4. Is the study set in Australia? & & & & \\
\hline 5. Is the paper qualitative in nature? & & & & \\
\hline $\begin{array}{l}\text { 6. Is it an interpretive study - } \\
\text { Phenomenology, ethnography, } \\
\text { grounded theory or a mixture? }\end{array}$ & & & & \\
\hline 7. Is the paper dated after $1990 ?$ & & & & \\
\hline
\end{tabular}

If 'yes' to above, include for appraisal. If 'no' to any of the above, then exclude paper as not meeting inclusion criteria. If "unsure" go on to appraisal and will compare to first appraisal. 
- Appendix II: Critical Appraisal Instrument

\section{NOTE:}

This figure/table/image has been removed to comply with copyright regulations. It is included in the print copy of the thesis held by the University of Adelaide Library. 
- Appendix III: Data Extraction Instrument

\section{NOTE:}

This figure/table/image has been removed to comply with copyright regulations. It is included in the print copy of the thesis held by the University of Adelaide Library. 


\section{- Appendix IV: Detailed Search Strategy}

Where possible databases and web sites were searched with the key terms as outlined below. Due to the variation in titles for advanced practice nurses, as well as the difficulties in searching for qualitative studies, a broad search strategy was used and many reference lists from retrieved papers were hand searched.

\section{Search Strategy for PubMed}

1. advanced practice nurs* [tiab] OR clinical nurse consultant [tiab] OR nurse practitioner [tiab] OR clinical nurse specialist [tiab] OR higher

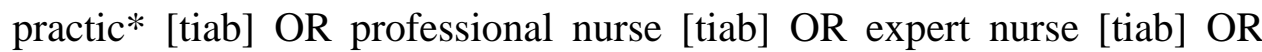
extended practice [tiab]

2. hospital [mh] OR acute care [tw] OR tertiary care cent* [tw] OR metropolitan [tw] OR rural hospital [tw] OR remote hospital [tw]

3. ethnograph* [tw] OR interpretive study [tw] OR phenomenolog* [tiab] OR grounded theory [tiab]OR thematic analysis [tiab] OR focus group [tiab] OR hermeneutic*[tiab] OR qualitative research [mh:exp] OR qualitative study [tw]OR interview [tw] OR experience [tiab]OR lived experience [tiab] OR narrative analysis [tw] OR mixed method [tw]OR interpretive synthesis [tw] OR meta synthesis [tw]

4. Australia [tiab]

5. \#1 AND \#2 AND \#3 AND \#4

AND (("1990/01/01"[PDat] : "2011/10/01"[PDat])) 


\section{Search strategy for CINAHL}

1. (MH "Advanced Practice Nurses+") OR "clinical nurse consultant" TX OR "expert nurse" TX OR "nurse practitioner+" MH OR "higher practice" TX OR "extended practice" TXOR "professional nurse" TX OR "expert nurse" TX OR "clinical nurse specialist" TX OR "advanced practice" TX

2. "Acute Care" MM OR metropolitan TX OR "Hospitals, Rural" MH OR "Hospitals, Urban" MH OR hospital TX OR tertiary care cent* TX

3. Australia AB

4. (MH "Qualitative Studies+") OR "Ethnographic Research" MH OR "Grounded Theory" MH OR "Naturalistic Inquiry" MH OR "Phenomenological Research" MH OR "interpretive research" TX OR " interpretive study" TX OR "lived experience" TX OR experience TX OR focus group TX OR interview TX OR hermeneutic*TX

5. S1 AND S2 AND S3 AND S4

6. Date limited 1990 - October 2011 


\section{Search Strategy for Embase}

\#1: advanced AND practice AND 'nurse'/exp OR (clinical AND 'nurse'/exp AND 'consultant'/exp) OR ('nurse'/exp AND 'practitioner'/exp) OR (higher AND practice) OR (extended AND practice) OR (professional AND 'nurse'/exp) OR (expert AND 'nurse'/exp) OR (clinical AND 'nurse'/exp AND 'specialist'/exp) OR (advanced AND practice)

\#2: 'australia'/exp/mj

\#3: acute AND care OR metropolitan OR (hospitals, AND rural) OR (hospitals, AND urban) OR 'hospital'/exp/mj OR tertiary

\#4: qualitative AND studies OR (ethnographic AND 'research'/exp) OR (grounded AND 'theory'/exp) OR (naturalistic AND inquiry) OR (phenomenological AND 'research'/exp) OR (interpretive AND 'research'/exp) OR (interpretive AND 'study'/exp) OR (lived AND 'experience'/exp) OR 'experience'/exp OR (focus AND group) OR 'interview'/exp OR hermeneutic

\#5: \#1 AND \#2 AND \#3 AND \#4

Australia/New Zealand Reference Centre (as for Embase)

\section{Informit Search strategy}

1. higher practice $\mathrm{OR}$ extended practice $\mathrm{OR}$ expert nurse $\mathrm{OR}$ advanced practice OR advanced practice nur* OR nurse practitioner OR clinical nurse consultant OR clinical nurse specialist OR professional nurse

2. urban hospital OR acute care OR metropolitan OR tertiary care cent* OR hospital OR rural hospital

3. Australia (any field) 
4. focus group $\mathrm{OR}$ interpretive $\mathrm{OR}$ experience $\mathrm{OR}$ lived experience $\mathrm{OR}$ interview OR qualitative stud* OR grounded theory OR ethnograph* OR phenomenolog* OR hermeneutic OR qualitative research OR narrative analysis OR mixed method OR thematic analysis

5. \#1 AND \#2 AND \#3 AND \#4

Date limited 1990 - October 2011

\section{Libraries Australia: The National Bibliographic Database}

Search Terms included:

Advanced practice

Advanced practice Nurse

Clinical nurse consultant

Nurse Practitioner

APN

Advanced practice nurse

Clinical nurse consultant

(Nurse practitioner) and (acute care)

(Advanced practice) and (acute care)

(Advanced practice nurse) and (acute care)

Clinical nurse specialist

Clinical nurse specialist + acute care+ (limits: 1990; Australian)

Advanced practice nurse + acute care + (limits: 1990; Australian)

Clinical nurse consultant + acute care + (limits: 1990; Australian)

(Expert nurse)

(Expert nurse $)+($ acute care $)$ 
(Expert nurse) $+($ hospital)

(Nurse practitioner) and (hospital)

(Advanced practice nurse) and (hospital)

\section{Australian Government Websites Search strategy}

Australian Institute for Health and Welfare) AIHW - http://www.aihw.gov.au/

Publications catalogue searched; search terms - nursing, nurse. Website contains mainly statistical information therefore was not relevant to this topic

Department of Health and Ageing - http://www.health.gov.au/

Publications catalogue searched with predetermined search term - nursing

National Health and Medical Research Council (NHMRC) http://www.nhmrc.gov.au/

Publications catalogue searched by subject and individual search terms: advanced practice, nursing, workforce, clinical nurse - no relevant publications returned. Database is more appropriate for clinical research and guideline development.

\section{Professional nursing associations}

\section{Royal College of Nursing Australia (RCNA)}

All table of contents of issues of the Collegian publication dated from 1/03/1990 to current day were hand searched.

Australian Nursing and Midwifery Council (ANMC)

http://www.anmc.org.au/ Publications catalogue searched but no relevant papers were found at this website.

\section{ANF (Australian Nursing Federation)}


All available online issues of the Australian Journal of Advanced Nursing (1995 to October 2011) and the Australian Nursing Journal (1993 to October 2011) were searched.

\section{Australian Health Practitioners Registration Association (AHPRA)}

http://www.ahpra.gov.au/ Publications catalogue searched but no relevant papers were found at this website.

\section{Coalition of National Nursing Organisations (CoNNO)}

http://www.conno.org.au/ No relevant publications found for appraisal

Other Australian Health organisational websites

Australian Healthcare Reform Alliance:

http://www.healthreform.org.au/ No relevant publications found for appraisal Australian Indigenous Health Infonet:

http://www.healthinfonet.ecu.edu.au/ No relevant publications found for appraisal 


\section{- Appendix V: Excluded Studies}

Gardner, G., A. Chang, and C. Duffield. Making nursing work: breaking through the role confusion of advanced practice nursing. Journal of Advanced Nursing, 2007. 57(4): p. 382-391. Reason for exclusion: Data representation incongruent to review objective; data presented according to model to support APN roles rather than exploring the experience of being APN/CNC.

Bloomer, M.J. and W.M. Cross, An exploration of the role and scope of the clinical nurse consultant (CNC) in a metropolitan health service. Collegian, 2011. 18(2): p. 61-9. Reason for exclusion: This paper was initially considered for inclusion after critical appraisal; however the paper was excluded after clarifying setting with authors, as it included nurses working in sub-acute and community settings.

Santiano, N., Young, L., Baramy, L. S., McDonnell, S., Page, K., Cabrera, R., \& Chapman, A. How do CNCs construct their afterhours support role in a major metropolitan hospital. Collegian (Deakin ACT), 2009. 16(2): p. 85-97. Reason for exclusion: Data representation incongruent to review objective; data represented according to competency framework, not as the experience of being APN/CNC.

Chaboyer, W., Foster, M. M., Foster, M., \& Kendall, E., The Intensive Care Unit liaison nurse: towards a clear role description. Intensive \& Critical Care Nursing, 2004. 20: p. 77-86. Reason for exclusion: Data representation incongruent to review objective/ incongruence between methodology and representation of results.

Vaughan, K., Wilkes, L. M., O'Baugh, J., \& O'Donohue, R. The role and scope of the clinical nurse consultant in Wentworth Area Health Service: a qualitative study. Collegian, 2005. 12(3): p. 14-19. Reason for exclusion: Incongruence between methodology and interpretation of results/ data representation incongruent to review objective. 


\section{- Appendix VI: Categories for metasynthesis}

\begin{tabular}{|c|c|c|}
\hline Category & $\begin{array}{l}\text { Number of } \\
\text { findings }\end{array}$ & Description \\
\hline 1 - Expert knowledge & 19 & $\begin{array}{l}\text { Expert knowledge is required, utilised and is } \\
\text { ongoing. }\end{array}$ \\
\hline $\begin{array}{c}2 \text { - Routine daily } \\
\text { activities }\end{array}$ & 5 & $\begin{array}{l}\text { APNs experience a certain amount of routine in } \\
\text { their daily work. }\end{array}$ \\
\hline 3 - Education & 9 & $\begin{array}{l}\text { APNs are an educational resource for their } \\
\text { departments and spend a large amount of time } \\
\text { educating peers, staff, patients and their families. }\end{array}$ \\
\hline $\begin{array}{l}4 \text { - Administrative } \\
\text { work }\end{array}$ & 4 & $\begin{array}{l}\text { Having to do large component of administrative } \\
\text { work detracts APNs from patient care and } \\
\text { contributes to overtime, work overload and } \\
\text { frustration. }\end{array}$ \\
\hline $\begin{array}{l}\text { - } \begin{array}{l}\text { Confidence } \\
\text { influences } \\
\text { practice }\end{array} \\
\end{array}$ & 23 & $\begin{array}{l}\text { Confidence in their role allows APNs to make } \\
\text { quick and effective decisions, time manage, } \\
\text { prioritise and bypass hierarchy if required. }\end{array}$ \\
\hline $\begin{array}{l}6 \text { - Multi-dimensional } \\
\text { role }\end{array}$ & 22 & $\begin{array}{l}\text { APNs work in diverse areas with varying } \\
\text { management responsibilities and functions. They } \\
\text { may work independently or interdependently. }\end{array}$ \\
\hline $\begin{array}{l}7 \text { - Organisational } \\
\text { factors }\end{array}$ & 10 & $\begin{array}{l}\text { APNs can be frustrated by organisational } \\
\text { protocols that affect service delivery. }\end{array}$ \\
\hline $\begin{array}{l}8 \text { - Negative } \\
\text { experiences }\end{array}$ & 27 & $\begin{array}{l}\text { Negative experiences with staff relationships, } \\
\text { organisation and workload can impact greatly on } \\
\text { nurse at a personal and professional level. }\end{array}$ \\
\hline $\begin{array}{l}9 \text { - Intuitive } \\
\text { knowledge }\end{array}$ & 6 & $\begin{array}{l}\text { APNs may conduct their practice intuitively and } \\
\text { instinctively at times. }\end{array}$ \\
\hline 10 - Relationships & 17 & $\begin{array}{l}\text { Multidisciplinary relationship building and } \\
\text { maintaining positive relationships is essential to } \\
\text { positive experience. }\end{array}$ \\
\hline $\begin{array}{l}11 \text { - Responsibility } \\
\text { and } \\
\text { accountability }\end{array}$ & 9 & $\begin{array}{l}\text { APNs are very mindful of the responsibility they } \\
\text { have and that they are accountable for their } \\
\text { decisions. }\end{array}$ \\
\hline $\begin{array}{l}12 \text { - Supportive } \\
\text { resource }\end{array}$ & 11 & $\begin{array}{l}\text { APNs provide support to staff, patients and } \\
\text { families. }\end{array}$ \\
\hline 13 - Patient care & 21 & The patient is central to their experience. \\
\hline $\begin{array}{l}14 \text { - Familiarity and } \\
\text { clinical } \\
\text { experience }\end{array}$ & 6 & $\begin{array}{l}\text { APNs exhibit familiarity with tasks and have the } \\
\text { ability to use their experience to deal with a } \\
\text { variety of issues. }\end{array}$ \\
\hline $\begin{array}{l}15 \text { - Communication } \\
\text { skills }\end{array}$ & 5 & $\begin{array}{l}\text { APNs demonstrate effective, expert } \\
\text { communications skills. }\end{array}$ \\
\hline $\begin{array}{l}16 \text { - Positive } \\
\text { experiences }\end{array}$ & 11 & $\begin{array}{l}\text { APNs have positive and rewarding experiences } \\
\text { which are usually related to positive patient care } \\
\text { experiences. }\end{array}$ \\
\hline 17 - Consultancy role & 5 & $\begin{array}{l}\text { Consultancy and liaison can be extensive and may } \\
\text { link their own unit to other departments and } \\
\text { sometimes outside the hospital environment. }\end{array}$ \\
\hline $\begin{array}{c}18 \text { - Professional } \\
\text { behaviour }\end{array}$ & 6 & $\begin{array}{l}\text { Acting in a professional manner in all } \\
\text { circumstances is paramount to APN experience. }\end{array}$ \\
\hline
\end{tabular}




\section{References}

Appel, A., Malcolm, P. A., \& Nahas, V. (1996). Nursing Specialization in New South Wales, Australia. Clinical Nurse Specialist, 10(2), 76-81.

Arbon, P. (2004). Understanding experience in nursing. Journal of Clinical Nursing(13), 150-157.

Australian Nursing and Midwifery Council. (2004). Nurse Practitioner Standards Project Final Report. Canberra: Australian Nursing and Midwifery Council/Royal College of Nursing Australia Retrieved from http://www.anmc.org.au/.

Benner, P., \& Tanner, C. (1987). Clinical Judgment: How Expert Nurses Use Intuition. The American Journal of Nursing, , 87(1), 23-31.

Bloomer, M. J., \& Cross, W. M. (2011). An exploration of the role and scope of the clinical nurse consultant (CNC) in a metropolitan health service. Collegian, 18(2), 61-69.

Borbasi, S. A. (1999). Advanced practice/expert nurses: hospitals can't live without them. Australian Journal of Advanced Nursing, 16(3), 21-29.

Bryant-Lukosius, D., et al.,. (2004). Advanced practice nursing roles: development, implementation and evaluation. Journal of Advanced Nursing, 48(5), 519-529.

Buchan, J. (2000). Planning for change: developing a policy framework for nursing labour markets. International Nursing Review, 47(4), 199-206.

Buchan, J., \& Aiken, L. (2008). Solving nursing shortages: a common priority. Journal of Clinical Nursing, 17(24), 3262-3268.

Bull, S., \& Hart, G. (1995). Clinical Nurse Specialist: Walking the wire. Contemporary Nurse, 4, 25-32

Chaboyer, W., Foster, M. M., Foster, M., \& Kendall, E. (2004). The Intensive Care Unit liaison nurse: towards a clear role description. Intensive \& Critical Care Nursing, 20, 77-86.

Cohen, M. Z., Kahn, D. L., \& Steeves, R. H. (2000). Hermeneutic Phenomenological Research: A Practical Guide for Nurse Researchers. Thousand Oaks: Sage.

Coombs, M., Chaboyer, W., \& Sole, M. L. (2007). Advanced nursing roles in critical care-A natural or forced evolution? . Journal of Professional Nursing, 23(2), 83-90. 
Currie, L., \& Watterson, L. (2009). Investigating the role and impact of expert nurses. British Journal of Nursing, 18(13), 816-824.

Daly, W. M., \& Carnwell, R. (2003). Nursing roles and levels of practice: a framework for differentiating between elementary, specialist and advancing nursing practice. Journal of Clinical Nursing, 12(2), 158-167.

Di Censo, A. (2008). Roles, research \& resilience: The evolution of advanced practice nursing. Canadian Nurse, 104(9), 37-40.

Dixon-Woods, M., Bonas, S., Booth, A., Jones, D. R., Miller, T., Sutton, A. J., . . . Young, B. (2006). How can systematic reviews incorporate qualitative research? A critical perspective. Qualitative Research, 6(1), 27-44. doi: $10.1177 / 1468794106058867$

Dopson, S., Fitzgerald, L., \& Ferlie, E. (2008). Understanding Change and Innovation in Healthcare Settings: Reconceptualizing the Active Role of Context. Journal of Change Management, 8(3-4), 213-231.

Duffield, C., Chang, A., Fry, M., \& Stasa, H. (2011). National regulation in Australia: A time for standardisation in roles and titles. Collegian, 18(2), 45-49. doi: 10.1016/j.colegn.2011.01.002

Duffield, C., Gardner, G., Chang, A., \& Catling-Paull, C. (2009). Advanced nursing practice: a global perspective. Collegian: Journal of the Royal College of Nursing Australia, 16(2), 55-62.

Elsom, S., Happell, B., \& Manias, E. (2005). Mental health nurse practitioner : expanded or advanced? International Journal of Mental Health Nursing, 14(3), 181-186.

Elsom, S., Happell, B., \& Manias, E. (2006). The clinical nurse specialist and nurse practitioner roles: room for both or take your pick? Australian Journal of Advanced Nursing 24(2), 56-59.

Gardner, G., Chang, A., \& Duffield, C. (2007). Making nursing work: breaking through the role confusion of advanced practice nursing. Journal of Advanced Nursing, 57(4), 382-391.

Guba, E. G. (1981). Criteria for Assessing the Trustworthiness of Naturalistic Inquiries. Educational Communication and Technology Journal, 29(2), 75-91.

Hannes, K., \& Harden, A. (2012). Multi-context versus context-specific qualitative evidence syntheses: combining the best of both. Research Synthesis Methods, 2, 271-278. doi: 10.1002/jrsm.55 
Hanson, C. M., \& Hamric, A. B. (2003). Reflections on the Continuing Evolution of Advanced Nursing Practice. Nursing Outlook, 51(5), 203-211.

Heartfield, M. (2006). Specialisation and Advanced Practice Discussion Paper. Melbourne: Nursing \& Nursing Education Taskforce (N3ET) Retrieved from http://www.nnnet.gov.au/National

Holloway, K., Baker, J., \& Lumby, J. (2009). Specialist nursing framework for New Zealand: A missing link in workforce planning. Policy, Politics, \& Nursing Practice, 10(4), 269-275.

International Council of Nurses. (2001). Definition and Characteristics of the role. http://icn-apnetwork.org/

Jamieson, L., \& Williams, L. M. (2002). Confusion prevails in defining 'Advanced nursing practice'. Collegian: Journal of the Royal College of Nursing Australia, 9(4), 29-33.

Jones, J. S., \& Minarik, P. A. (2012). The Plight of the Psychiatric Clinical Nurse Specialist: The Dismantling of the Advanced Practice Nursing Archetype. Clinical Nurse Specialist, 26(3), 121-125. www.cnsjournal.com doi:10.1097/NUR.0b013e318256855a

Ketefian, S., Redman, R. W., Hanucharurnkul, S., Masterson, A., \& Neves, E. P. (2001). The development of advanced practice roles: implications in the international nursing community. International Nursing Review, 48(3), 152-163.

Lloyd Jones, M. (2005). Role development and effective practice in specialist and advanced practice roles in acute hospital settings: systematic review and meta-synthesis. Journal of Advanced Nursing, 49(2), 191209.

MacDonald, J., Herbert, R., \& Thibeault, C. (2006). Advanced Practice Nursing: Unification through a common identity. Journal of Professional Nursing, 22, 172-179.

Mantzoukas, S., \& Watkinson, S. (2007). Review of advanced nursing practice: the international literature and developing the generic features. Journal of Clinical Nursing, 16(1), 28-37.

McCormack, B., Kitson, A., Harvey, G., Rycroft-Malone, J., Titchen, A., \& Seers, K. (2002). Getting evidence into practice: the meaning of 'context'. Journal of Advanced Nursing, 38(1), 94-104.

McCutcheon, H., \& Pincombe, J. (2001). Intuition: an important tool in the practice of nursing. Journal of Advanced Nursing, 35(5), 342-348. 
McInerney, P., \& Brysiewicz, P. (2009). A systematic review of the experiences of caregivers in providing home-based care to persons with HIV/AIDS in Africa. JBI Library of Systematic Reviews, 7(4), 130153.

Mick, D. J., \& Ackerman, M. H. (2002). Deconstructing the myth of the advanced practice blended role: Support for role divergence. Heart \& Lung, 31(6), 393-398.

Morse, J. M., Swanson, J. M., \& Kuzel, A. J. (Eds.). (2001). The Nature of Qualitative Evidence. Thousand Oaks: Sage Publications.

Newhouse, R. P., Stanik-Hutt, J., White, K. M., Johantgen, M., Bass, E. B., Zangaro, G., . . . Weiner, J. P. (2011). Advanced Practice Nurse Outcomes 1990-2008: A Systematic Review. Nursing Economics, 29(5), $1-22$.

Nooney, J. G., Unruh, L., \& Yore, M. M. (2010). Should I stay or should I go? Career change and labor force separation among registered nurses in the US. Social Science \& Medicine, 70(12), 1874-1881.

NSW Health. (2005). Clinical Nurse Consultant - Higher Grades - Public Hospital Nurses' (State) Award. Sydney: NSW Health Retrieved from http://www.health.nsw.gov.au/policies/.

O'Baugh, J., Wilkes, L. M., Vaughan, K., \& O'Donohue, R. (2007). The role and scope of the clinical nurse consultant in Wentworth are health service, New South Wales, Australia. Journal of Nursing Management,, 15, 1221.

O'Connor, M., \& Chapman, Y. (2008). The palliative care clinical nurse consultant: an essential link. Collegian, 15(4), 151-157.

Offredy, M. ( 2000). Advanced nursing practice: the case of nurse practitioners in three Australian states. Journal of Advanced Nursing, 31(2), 274-281.

Paterson, B. L., Thorne, S. E., Canam, C., \& Jillings, C. (2001). Meta-Study of Qualitative Health Research. Thousand Oaks: Sage Publications.

Pearson, A. (2004). Balancing the evidence: incorporating the synthesis of qualitative data into systematic reviews JBI Reports (Vol. 2, pp. 45-64). Adelaide.

Pearson, A., Lockwood, C., Florence, Z., \& Thomas, P. (2008). A framework for advanced practice nursing and midwifery: consultation paper. Adelaide: SA Health.

Pearson, A., \& Peels, S. (2002). Advanced practice in nursing: International perspective. International Journal of Nursing Practice, 8(2), S1-S4. 
Pearson, A., Wiechula, R., Court, A., \& Lockwood, C. (2005). The JBI model of evidence-based healthcare. International Journal of Evidence Based healthcare, 3, 207-215.

Pope, C. (2003). Resisting Evidence: The Study of Evidence-based Medicine as a Contemporary Social Movement. Health, 7(3), 267-282.

Por, J. (2008). A critical engagement with the concept of advancing nursing practice. . Journal of Nursing Management 16(1), 84-90.

Pulcini, J., Jelic, M., Gul, R., \& Loke, A. Y. (2010). An international survey on advanced practice nursing education, practice, and regulation Journal of Nursing Scholarship, 42(1), 31-39.

Rew, L., \& Barrow, E. M. (2007). State of the Science Intuition in Nursing, a Generation of Studying the Phenomenon. Advances in Nursing Science, 30(1), E15-E25.

Rice, P., \& Ezzy, D. (1999). Qualitative Research Methods: A Health Focus. Melbourne: Oxford University Press.

Royal College of Nursing Australia. (2006). Position Statement: Advanced Practice Nursing. Deakin West: RCNA Retrieved from http://www.rcna.org.au.

Santiano, N., Young, L., Baramy, L. S., McDonnell, S., Page, K., Cabrera, R., \& Chapman, A. (2009). How do CNCs construct their after hours support role in a major metropolitan hospital. Collegian, 16(2), 85-97.

Sandelowski, M., \& Barroso, J. (2007). Handbook for Synthesizing Qualitative Research. New York: Springer Publishing Company.

Schuetz, A. (1953). Common-Sense and Scientific Interpretation of Human Action. Philosophy and Phenomenological Research, 14(1), 1-38.

Scott, S., Estabrooks, C. A., Allen, M., \& Pollock, C. (2008). A Context of Uncertainty: How Context Shapes Nurses' Research Utilization Behaviors. Qualitative Health Research(18), 347-357.

Seale, C. (1999). Quality in qualitative research. Qualitative Inquiry, 5(4), 465478.

Sheer, B., \& Wong, F. K. Y. (2008). The development of advanced nursing practice globally. Journal of Nursing Scholarship, 40(3), 204-211.

Shenton, A. (2004). Strategies for ensuring trustworthiness in qualitative research projects. Education for Information, 2, 63-75. 
Taylor, A. (1999). Advanced Practice and the Orthopaedic Nurse: An Interpretive Study. (Master of Nursing), University of Adelaide, Adelaide.

The Joanna Briggs Institute. (2008). Reviewer's Manual 2008 edition. Adelaide.

Van Manen, M. (1990). Researching Lived Experience. New York: State University of New York Press.

Vaughan, K., Wilkes, L. M., O'Baugh, J., \& O'Donohue, R. (2005). The role and scope of the clinical nurse consultant in Wentworth Area Health Service: a qualitative study. Collegian, 12(3), 14-19.

Walters, A. J. (1996). Being a clinical nurse consultant: A hermeneutic phenomenological reflection. International Journal of Nursing Practice, 2(1), 2-10. 